Article

\title{
Autosomal Dominant Gyrate Atrophy-Like Choroidal Dystrophy Revisited: 45 Years Follow-Up and Association with a Novel C1QTNF5 Missense Variant
}

\author{
Ulrich Kellner ${ }^{1,2, *,+} \mathbb{D}$, Nicole Weisschuh ${ }^{3,+}$, Silke Weinitz ${ }^{1,2}$, Ghazaleh Farmand ${ }^{1}$, Sebastian Deutsch ${ }^{1} \mathbb{D}$, \\ Friederike Kortüm ${ }^{4}$, Pascale Mazzola ${ }^{5}$, Karin Schäferhoff ${ }^{5}$, Valerio Marino ${ }^{6}$ (D) and Daniele Dell’Orco ${ }^{6}$ (D)
}

1 Zentrum für Seltene Netzhauterkrankungen, AugenZentrum Siegburg, MVZ Augenärztliches Diagnostikund Therapiecentrum Siegburg GmbH, Europaplatz 3, 53721 Siegburg, Germany; weinitz@augenzentrum-siegburg.de (S.W.); farmand@augenzentrum-siegburg.de (G.F.); deutsch.bastian@googlemail.com (S.D.)

2 RetinaScience, Postfach 301212, 53192 Bonn, Germany

3 Center for Ophthalmology, Institute for Ophthalmic Research, University of Tübingen, 72076 Tübingen, Germany; nicole.weisschuh@uni-tuebingen.de

4 Center for Ophthalmology, University Eye Hospital, University of Tübingen, 72076 Tübingen, Germany; friederike.kortuem@uni-tuebingen.de

5 Institute of Medical Genetics and Applied Genomics, University of Tübingen, 72076 Tübingen, Germany; pascale.mazzola@med.uni-tuebingen.de (P.M.); karin.schaeferhoff@med.uni-tuebingen.de (K.S.)

Citation: Kellner, U.; Weisschuh, N.; Weinitz, S.; Farmand, G.; Deutsch, S.; Kortüm, F.; Mazzola, P.; Schäferhoff, K.; Marino, V.; Dell'Orco, D. Autosomal Dominant Gyrate Atrophy-Like Choroidal Dystrophy Revisited: 45 Years Follow-Up and Association with a Novel C1QTNF5 Missense Variant. Int. J. Mol. Sci. 2021, 22, 2089. https://doi.org/ $10.3390 /$ ijms22042089

Academic Editor: Akiko Maeda

Received: 30 December 2020

Accepted: 17 February 2021

Published: 19 February 2021

Publisher's Note: MDPI stays neutral with regard to jurisdictional claims in published maps and institutional affiliations.

Copyright: (C) 2021 by the authors Licensee MDPI, Basel, Switzerland. This article is an open access article distributed under the terms and conditions of the Creative Commons Attribution (CC BY) license (https:/ / creativecommons.org/licenses/by/ $4.0 /)$.
6 Department of Neurosciences, Biomedicine and Movement Sciences, Section of Biological Chemistry, University of Verona, 37134 Verona, Italy; valerio.marino@univr.it (V.M.); daniele.dellorco@univr.it (D.D.)

* Correspondence: kellneru@mac.com

+ Both authors should be considered shared first authors.

Abstract: We present a long-term follow-up in autosomal dominant gyrate atrophy-like choroidal dystrophy (adGALCD) and propose a possible genotype/phenotype correlation. Ophthalmic examination of six patients from two families revealed confluent areas of choroidal atrophy resembling gyrate atrophy, starting in the second decade of life. Progression continued centrally, reaching the fovea at about 60 years of age. Subretinal deposits, retinal pigmentation or choroidal neovascularization as seen in late-onset retinal degeneration (LORD) were not observed. Whole genome sequencing revealed a novel missense variant in the C1QTNF5 gene (p.(Q180E)) which was found in heterozygous state in all affected subjects. Haplotype analysis showed that this variant found in both families is identical by descent. Three-dimensional modeling of the possible supramolecular assemblies of C1QTNF5 revealed that the p.(Q180E) variant led to the destabilization of protein tertiary and quaternary structures, affecting both the stability of the single protomer and the entire globular head, thus exerting detrimental effects on the formation of C1QTNF5 trimeric globular domains and their interaction. In conclusion, we propose that the p.(Q180E) variant causes a specific phenotype, adGALCD, that differs in multiple clinical aspects from LORD. Disruption of optimal cell-adhesion mechanisms is expected when analyzing the effects of the point mutation at the protein level.

Keywords: autosomal dominant gyrate atrophy-like choroidal dystrophy (adGALCD); late-onset retinal dystrophy (LORD); C1QTNF5; genetic modeling; long-term follow-up

\section{Introduction}

Inherited diffuse choroidal dystrophies with peripheral onset include two well defined disorders, gyrate atrophy (MIM 258870) and choroideremia (MIM 303100) [1,2]. Gyrate atrophy is an autosomal recessively inherited disorder associated with mutations in the $O A T$ gene and hyperornithinemia [1]. Choroideremia is an $\mathrm{x}$-linked inherited disorder associated with mutations in the CHM gene [2]. Several simplex cases and few families which are not sufficiently defined to form another entity have been reported. Of these, autosomal dominant disorders include retinitis pigmentosa with predominant choroidal 
atrophy associated with a dominant RPE65 mutation [3] as well as a late-onset night blindness with trickle like macular dystrophy [4].

Autosomal dominant choroidal dystrophy has been rarely reported as diffuse choroidal dystrophy initially involving the posterior pole [5] and in few families with peripheral onset similar to gyrate atrophy. Some of the latter families were reported prior to the knowledge of the association of hyperornithinemia and gyrate atrophy [6]. One family was reported with exclusion of hyperornithinemia and the observed phenotype has been termed autosomal dominant gyrate atrophy-like choroidal dystrophy (adGALCD) [7].

Late-onset retinal degeneration (MIM 605670; LORD) is an autosomal dominantly inherited disorder with several distinct clinical signs, which include initially mid-peripheral temporal subretinal deposits developing into scalloped choroidal atrophy and progression towards the macula with choroidal neovascularization in later stages [8-10]. Most cases with LORD have been associated with the p.(S163R) variant in the C1QTNF5 gene, indicating that this particular variant is a founder mutation [11]. Few additional LORD families with different variants in the C1QTNF5 gene have been reported, including the recurrent p.(S163R) variant as well as additional missense variants (p.(P188T), p.(G216C), p.(P186S) and p.(S190W)) located in the gC1q domain of the C1QTNF5 protein [12,13] (Figure 1A,B).

The human C1QTNF5 gene encodes for a $25 \mathrm{kDa}$ secretory protein expressed in adipose tissue [14], ciliary body of the eye and in the retinal pigment epithelium (RPE) [15]. C1QTNF5 is composed by three domains, namely the signal peptide (residues 1-15), the collagen domain (residues 30-98) and the gC1q domain (residues 103-243) [11,16] (Figure 1A). Specifically, the collagen domain allows the association with the plasma membrane via collagen receptors, while the $\mathrm{gClq}$ domain is responsible for RPE cell adhesion with other RPE cells and with Bruch membrane [17,18] (Figure 1C). As a member of the C1q family [19], C1QTNF5 protomers assemble into trimers due to the intertwining of their collagen domains. The association of the collagen domains brings the $\mathrm{gClq}$ domains close to one another, thus favoring the packing of the hydrophobic "zipper" box at the protomer-protomer interface, ultimately leading to the constitution of a globular domain (or globular head). Additionally, six globular trimers furtherly assemble into a bouquet-like octadecameric multimer [18] via the association of their collagen triple helices (Figure 1C,D).

The hydrophobic plateau constituted by residues 181-186 of each protomer [16] gives rise to an extended hydrophobic surface responsible for the binding of an RPE cell [15] to a neighboring cell or to the underlying Bruch membrane [18].

The purpose of the present study was to present long-term follow-up of the original adGALCD family [7] and of a distantly related second family to better characterize the clinical course and the retinal morphology and function in this disorder. In addition, we report an association of adGALCD with a novel C1QTNF5 missense variant and discuss possible genotype/phenotype correlation based on in silico molecular analysis. 
A
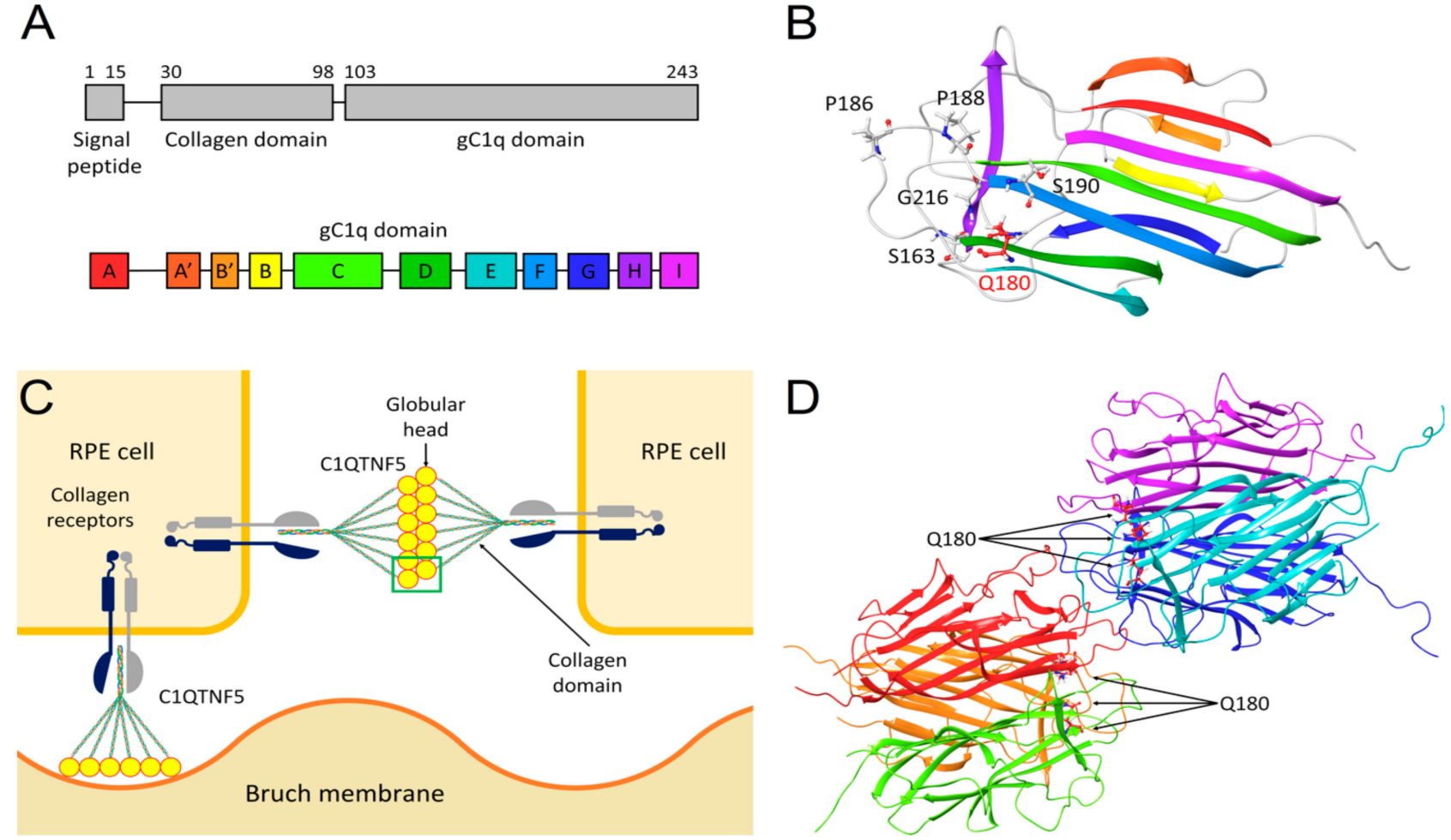

Figure 1. (A) Domain organization of C1QTNF5 (top) and secondary structure elements (bottom) with the coloring scheme and labeling of the individual $\beta$-strands. (B) The three-dimensional structure of a C1QTNF5 protomer is shown in cartoon, with $\beta$-strands colored according to panel A, residues S163, P186, P188, S190 and G216, whose mutations are late-onset retinal degeneration (LORD)-associated, are shown in grey sticks and labeled. Residue Q180, whose E variant is autosomal dominant gyrate atrophy-like choroidal dystrophy (adGALCD)-associated in this work, is represented in red sticks and labeled. $\mathrm{N}$ atoms are colored in blue, $\mathrm{O}$ atoms in red, $\mathrm{H}$ atoms in white. (C) Schematic representation of the C1QTNF5-mediated interactions of retinal pigment epithelium (RPE) cells with neighboring cells and with Bruch membrane. The collagen domain binds to collagen receptors on the membrane of an RPE cell, while the globular heads of the bouquet-like C1QTNF5 multimer can interact with the globular heads of another C1QTNF5 multimer bound to an adjacent RPE cell or with Bruch membrane. The structure of the two globular heads framed in green is represented in panel D. (D) Three-dimensional structure of the two trimers constituting the globular heads of C1QTNF5 belonging to different RPE cells and involved in cell adhesion based on available X-ray crystallographic data. Protein structure is shown in cartoon, chain A of is colored in red, chain B in orange, chain C in green, chains A, B and C of the second molecule are represented in cyan, blue and purple, respectively. Residues Q180 are shown as red sticks and labeled.

\section{Results}

\subsection{Clinical Evaluation of Family Members}

Two families were included in this study. For family BD 35 with three affected males, a father and his two sons, initial findings have been reported previously [7]. Ornithine blood levels were normal in all three patients. The mother of both sons (III:1) had normal findings at 68 years of age. The parents of patient III:2 died prior to 45 years of age without reported eye problems. The maternal grandmother of patient III:2 was reported to be affected. For one of the sons (IV:2), regular follow-up visits were undertaken between 38 and 63 years of age. In family ADRP 386, three affected siblings (IV:1, IV:2 and IV:3) were examined between 50 to 58 years of age. Further family members in three previous generations were reported to be affected (Figure 2) but were not available for clinical examination. 

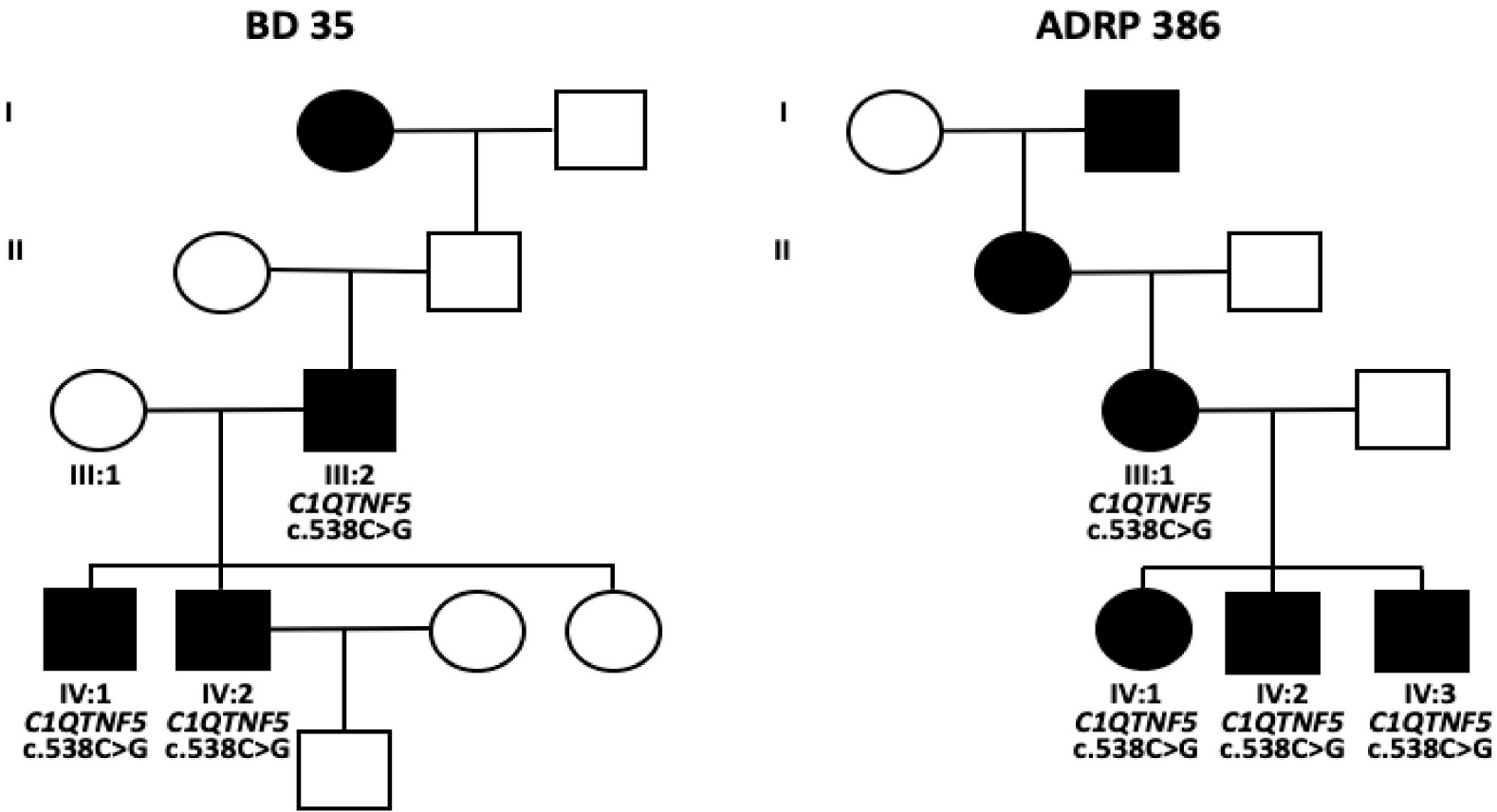

Figure 2. Pedigrees and genotypes of both families. I-IV: consecutive generations.

Onset of disease with peripheral atrophic lesions was documented in patient IV:2 from family BD 35 at 18 years of age and in patient IV:2 from family ADRP 386 at 24 years of age (Table 1). Functional problems were noted later at about 40 years of age (patients III:2 and IV:1 from family BD35; patients IV:2 and IV:3 from family ADRP 386) with the onset of night blindness. In the same patients, subjective problems due to visual field defects were noted at about 50 years of age.

Table 1. Patient data: examination, age of onset, refraction.

\begin{tabular}{|c|c|c|c|c|c|c|c|c|c|}
\hline ID & $\begin{array}{l}\text { Age First } \\
\text { Exam }\end{array}$ & $\begin{array}{l}\text { Age Last } \\
\text { Exam }\end{array}$ & $\begin{array}{l}\text { Follow-Up } \\
\text { in Years }\end{array}$ & $\begin{array}{l}\text { Age of } \\
\text { Onset }\end{array}$ & Eye & $\begin{array}{l}\text { Refraction } \\
\text { First Exam }\end{array}$ & $\begin{array}{l}\text { VA First } \\
\text { Exam }\end{array}$ & $\begin{array}{l}\text { Refraction } \\
\text { Last Exam }\end{array}$ & $\begin{array}{l}\text { VA Last } \\
\text { Exam }\end{array}$ \\
\hline \multicolumn{10}{|c|}{ BD 35} \\
\hline \multirow{2}{*}{ III:2 } & \multirow{2}{*}{40} & \multirow{2}{*}{70} & \multirow{2}{*}{30} & \multirow{2}{*}{$40 \mathrm{NB}$} & OD & NA & 1.0 & +1.0 & 0.16 \\
\hline & & & & & OS & NA & 1.0 & $\begin{array}{l}+0.50 \\
-1.25 / 64^{\circ}\end{array}$ & 0.16 \\
\hline \multirow{2}{*}{ IV:1 } & \multirow{2}{*}{41} & \multirow{2}{*}{ - } & \multirow{2}{*}{0} & \multirow{2}{*}{$40 \mathrm{NB}$} & OD & NA & 1.0 & - & - \\
\hline & & & & & OS & NA & 1.0 & - & - \\
\hline \multirow[t]{2}{*}{ IV:2 } & \multirow[t]{2}{*}{18} & \multirow[t]{2}{*}{63} & \multirow[t]{2}{*}{45} & \multirow{2}{*}{$\begin{array}{l}18 \mathrm{RA}, \\
\text { VFD }\end{array}$} & OD & $\begin{array}{l}+2.25 \\
-2.25 / 11^{\circ}\end{array}$ & 1.0 & $\begin{array}{l}-0.50 \\
-0.75 / 75^{\circ}\end{array}$ & 0.63 \\
\hline & & & & & OS & $\begin{array}{l}+2.25 \\
-1.75 / 172^{\circ}\end{array}$ & 1.0 & $\begin{array}{l}+3.25 \\
-1.25 / 166^{\circ}\end{array}$ & 0.63 \\
\hline \multicolumn{10}{|c|}{ ADRP 386} \\
\hline \multirow[t]{2}{*}{ IV:1 } & \multirow[t]{2}{*}{58} & \multirow[t]{2}{*}{-} & \multirow[t]{2}{*}{0} & & OD & $\begin{array}{l}-0.25 \\
-2.25 / 168^{\circ}\end{array}$ & 0.5 & - & - \\
\hline & & & & & OS & $\begin{array}{l} \pm 0.00 \\
-0.50 / 25^{\circ}\end{array}$ & 0.63 & - & - \\
\hline \multirow[t]{2}{*}{ IV:2 } & \multirow[t]{2}{*}{53} & \multirow[t]{2}{*}{-} & \multirow[t]{2}{*}{0} & \multirow{2}{*}{$\begin{array}{l}24 \mathrm{RA} \\
39 \mathrm{NB} \\
53 \mathrm{VFD}, \mathrm{P}\end{array}$} & OD & $\begin{array}{l}+1.75 \\
-1.50 / 94^{\circ}\end{array}$ & 1.0 & - & - \\
\hline & & & & & OS & $\begin{array}{l}+1.50 \\
-1.50 / 95^{\circ}\end{array}$ & 1.0 & - & - \\
\hline \multirow[t]{2}{*}{ IV:3 } & \multirow[t]{2}{*}{50} & \multirow[t]{2}{*}{56} & \multirow[t]{2}{*}{6} & \multirow{2}{*}{$\begin{array}{l}40 \mathrm{NB} \\
50 \mathrm{VFD}, \\
\mathrm{AP}, \mathrm{P}\end{array}$} & OD & $\begin{array}{l}-0.75 \\
-1.75 / 90^{\circ}\end{array}$ & 0.63 & $\begin{array}{l}-0.75 \\
-2.50 / 87^{\circ}\end{array}$ & 0.4 \\
\hline & & & & & OS & $\begin{array}{l}-0.25 \\
-1.50 / 85^{\circ}\end{array}$ & 0.63 & $\begin{array}{l}-1.75 \\
-1.50 / 95^{\circ}\end{array}$ & 0.25 \\
\hline
\end{tabular}

AP: adaptation problems, NB: night blindness, P: photophobia, RA: retinal alterations, VA: visual acuity, VFD: visual field defects, OD: right eye, OS: left eye. 
Snellen visual acuity ranged between 0.5 to 1.0 in less progressed stages and was reduced to 0.1 to 0.4 when the residual visual field was smaller than 10 degrees (Table 1). Refractive errors were most mildly hyperopic with moderate astigmatism.

Cataract surgery was performed in one of the patients by one of the authors (U.K.) without complications. In this patient (IV:2 from family BD 35) as well as in all other patients without prior cataract surgery no long anterior lens zonules were noted (Table 2).

Table 2. Patient data: Anterior segment, retinal and functional findings.

\begin{tabular}{|c|c|c|c|c|c|c|c|}
\hline ID & $\begin{array}{l}\text { Anterior } \\
\text { Segment }\end{array}$ & Retina & $\begin{array}{l}\text { Optic } \\
\text { Disc }\end{array}$ & ERG & Dark Adaptation & mfERG & Color Vision \\
\hline \multicolumn{8}{|c|}{ BD 35} \\
\hline III:2 & $\begin{array}{l}\text { IOL OU } \\
\quad(63)\end{array}$ & $\begin{array}{l}\text { Residual foveal } \\
\text { island, no } \\
\text { pigmentation }\end{array}$ & pale & $\begin{array}{l}\text { No residual } \\
\text { response }(52 / 62)\end{array}$ & ND & ND & ND \\
\hline IV:1 & normal & $\begin{array}{l}\text { Peripheral and } \\
\text { peripapillary } \\
\text { atrophic lesions, no } \\
\text { pigmentation }\end{array}$ & vital & ND & ND & ND & ND \\
\hline IV:2 & $\begin{array}{l}\text { normal, } \\
\text { IOL OD } \\
\quad(63)\end{array}$ & $\begin{array}{l}\text { Progressive } \\
\text { peripheral and } \\
\text { peripapillary } \\
\text { atrophic lesions, no } \\
\text { pigmentation }\end{array}$ & vital & $\begin{array}{l}\text { slightly abnormal } \\
(18) ; \text { Severely } \\
\text { reduced (42); No } \\
\text { residual responses } \\
\text { (54) }\end{array}$ & $\begin{array}{l}\text { Mildly increased } \\
\text { threshold (38) }\end{array}$ & $\begin{array}{l}\text { Centrally } \\
\text { preserved but } \\
\text { reduced responses, } \\
\text { normal implicit } \\
\text { time }(54)\end{array}$ & $\begin{array}{c}\text { Nagel } \\
\text { anomaloscope: } \\
\text { normal; } \\
\text { PD15 desaturated: } \\
\text { minor errors }\end{array}$ \\
\hline \multicolumn{8}{|c|}{ ADRP 386} \\
\hline IV:1 & $\begin{array}{l}\text { IOL OU } \\
\quad(54)\end{array}$ & $\begin{array}{c}\text { Peripheral and } \\
\text { peripapillary atrophy, } \\
\text { no pigmentation }\end{array}$ & vital & $\begin{array}{l}\text { Minimal photopic } \\
\text { residual response }\end{array}$ & $\begin{array}{l}\text { Increased threshold } \\
\text { for white, red, blue }\end{array}$ & ND & ND \\
\hline IV:2 & normal & $\begin{array}{c}\text { Peripheral and } \\
\text { peripapillary atrophy, } \\
\text { Minimal } \\
\text { pigmentation } \\
\text { OCT: OD mild ERM }\end{array}$ & vital & Residual responses & ND & $\begin{array}{l}\text { Centrally } \\
\text { preserved but } \\
\text { reduced, normal } \\
\text { implicit time }\end{array}$ & $\begin{array}{l}\text { PD15 desaturated } \\
\text { and saturated: } \\
\text { minor errors }\end{array}$ \\
\hline IV:3 & normal & $\begin{array}{c}\text { Progressive } \\
\text { peripheral and } \\
\text { peripapillary } \\
\text { atrophic lesions, } \\
\text { limited pigmentation, } \\
\text { cystoid macular } \\
\text { edema }\end{array}$ & vital & $\begin{array}{l}\text { No residual } \\
\text { responses }(50)\end{array}$ & $\begin{array}{c}\text { Markedly } \\
\text { increased threshold } \\
\text { for white, red, } \\
\text { blue (56) }\end{array}$ & $\begin{array}{l}\text { Centrally } \\
\text { preserved but } \\
\text { reduced responses, } \\
\text { normal implicit } \\
\text { time }(50)\end{array}$ & $\begin{array}{l}\text { PD15 desaturated } \\
\text { and saturated: } \\
\text { minor errors (56) }\end{array}$ \\
\hline
\end{tabular}

ERG: full-field electroretinography, mfERG multifocal ERG, IOL: intraocular lens, OU: both eyes, OD: right eye, ND: not done. For the three patients examined more than once, numbers in brackets indicate age of patient at the time of the examination.

Retinal findings started with peripheral and peripapillary chorioretinal atrophic lesions. The lesions presented as large atrophic areas which were sharply demarcated by small areas of preserved retinal pigment epithelium (RPE) between lesions (Figures 3 and 4). Thus, the findings resembled more the appearance of gyrate atrophy than choroideremia. During progression, the peripheral lesions circumferentially encroached towards the fovea, reaching first the inferior vascular arcades latest at 50 years of age (Figures 3 and 4). In contrast, the progression of the peripapillary atrophy from the disc towards the fovea was slow (Figure 4). In late stages (patients III:2 from family BD 35 and IV:3 from family ADRP 386) only the foveal area was preserved. Pigmented lesions were either absent or minimal. 


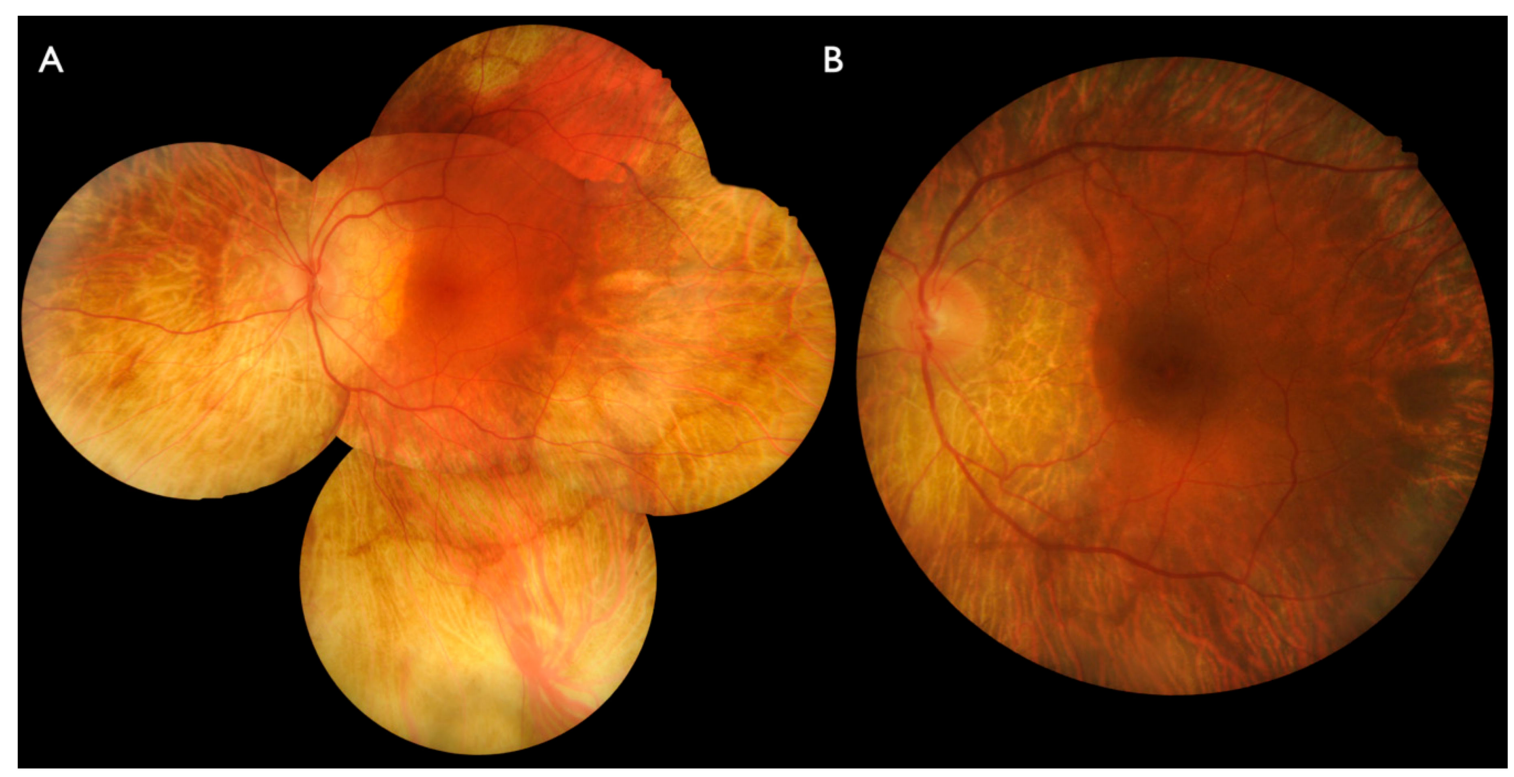

Figure 3. Fundus photography in family ADRP 386 in patient IV:2 at 53 years of age (A) and patient IV:3 at 56 years of age (B). Peripapillary atrophy is present in both patients. Peripheral confluent atrophic areas have approached to the macular area except from superior in patient IV:2, whereas circular atrophy up to the vascular arcades is present in patient IV:3.

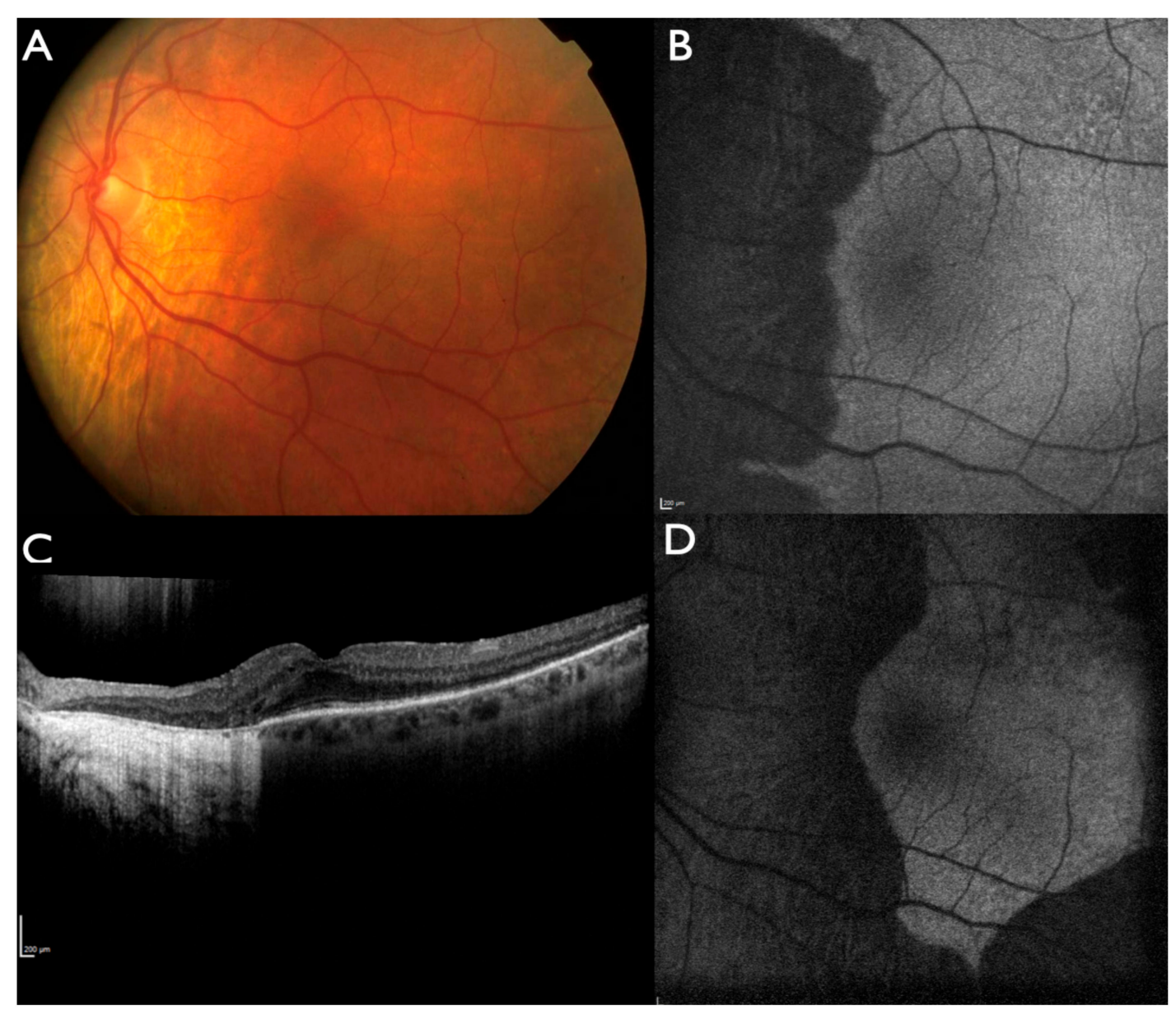

Figure 4. Progression of choroidal atrophy in patient IV:2 from family BD 35. Fundus photography at 38 years of age (A). Fundus autofluorescence at 51 years of age (B). Optical coherence tomography (OCT) (C) and fundus autofluorescence at 63 years of age (D). The progression of peripapillary atrophy towards the fovea is slow, whereas peripheral lesions progressed towards the posterior pole at age 63. 
Fundus autofluorescence (FAF), near-infrared autofluorescence (NIA) and optical coherence tomography (OCT) were normal in the non-affected regions with a sharp border towards the affected areas (Figures 4 and 5). Affected areas showed absence of FAF, NIA and a complete loss of outer retinal structures in the OCT indicating loss of photoreceptors and RPE. OCT-angiography showed absence of choriocapillaris and few remaining large choroidal vessels with reduced flow in the affected areas (patient IV:2 from family BD 35, Figure 6). Progression of disease could be documented over time (Figure 4). Only in patient IV:3 from family ADRP 386 cystoid macular edema was observed (Figure 5).



Figure 5. OCT of family ADRP 386 (patient IV:2 (A), patient IV:1 (B), patient IV:3 (C)). Peripapillary atrophy is associated with loss of retinal pigment epithelium and outer retinal layers. Those layers appear normal in the areas without atrophy, the border is sharply demarcated. Patient IV:1 shows some intraretinal fluid in the atrophic area, whereas patient IV:3 presents with cystoid macular edema. 

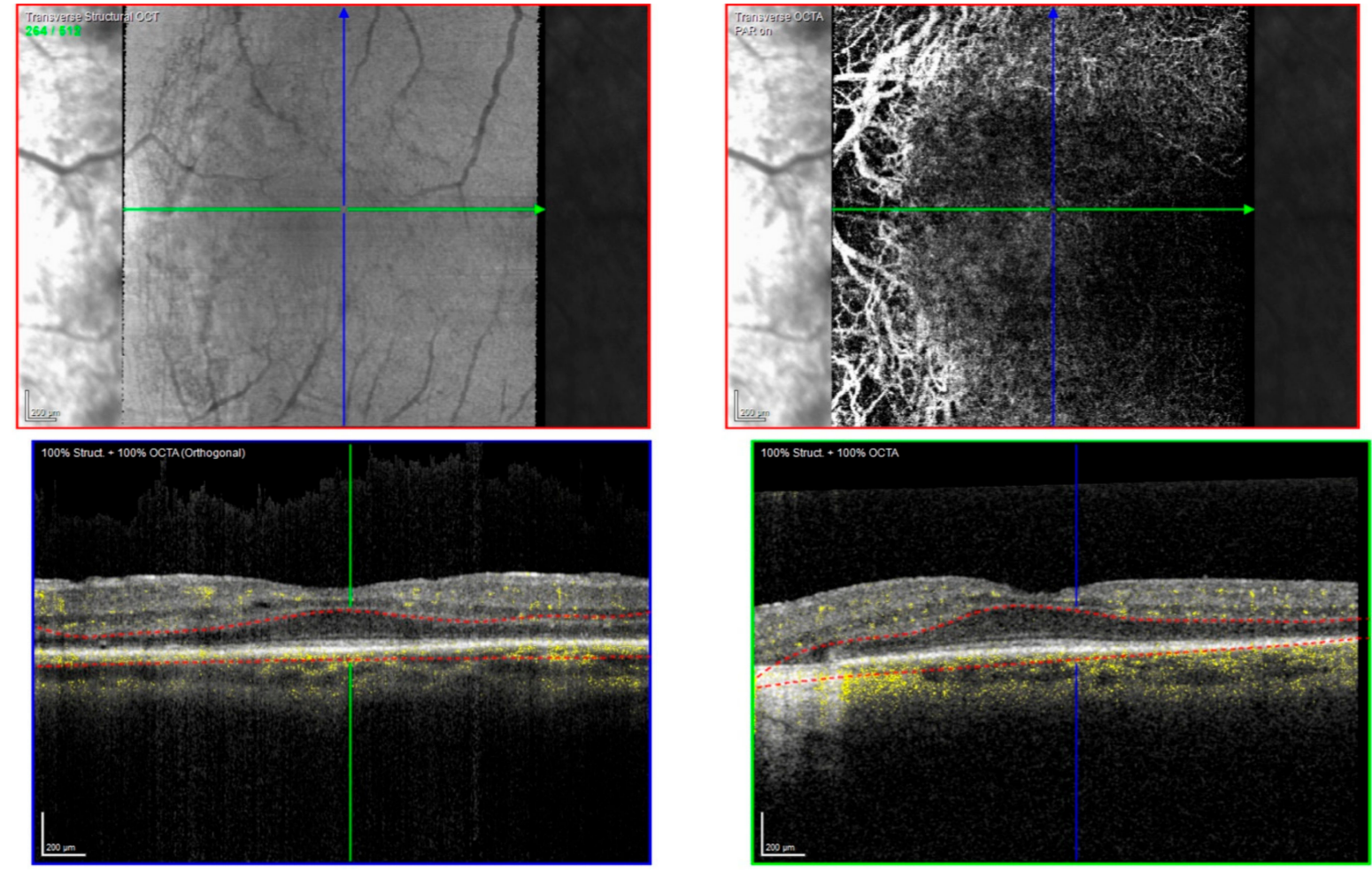

Figure 6. OCT-angiography on the left eye of patient IV:2 from family BD 35 with OCT-C-Scan (upper left), OCT angiography (upper right) and corresponding OCT-B-Scans below. Marked choriocapillaris and choroidal vessel atrophy is present in the atrophic areas.

Visual fields were variably constricted corresponding to the chorioretinal atrophic lesions and scotomata progressed similarly over time (Figures 7 and 8).
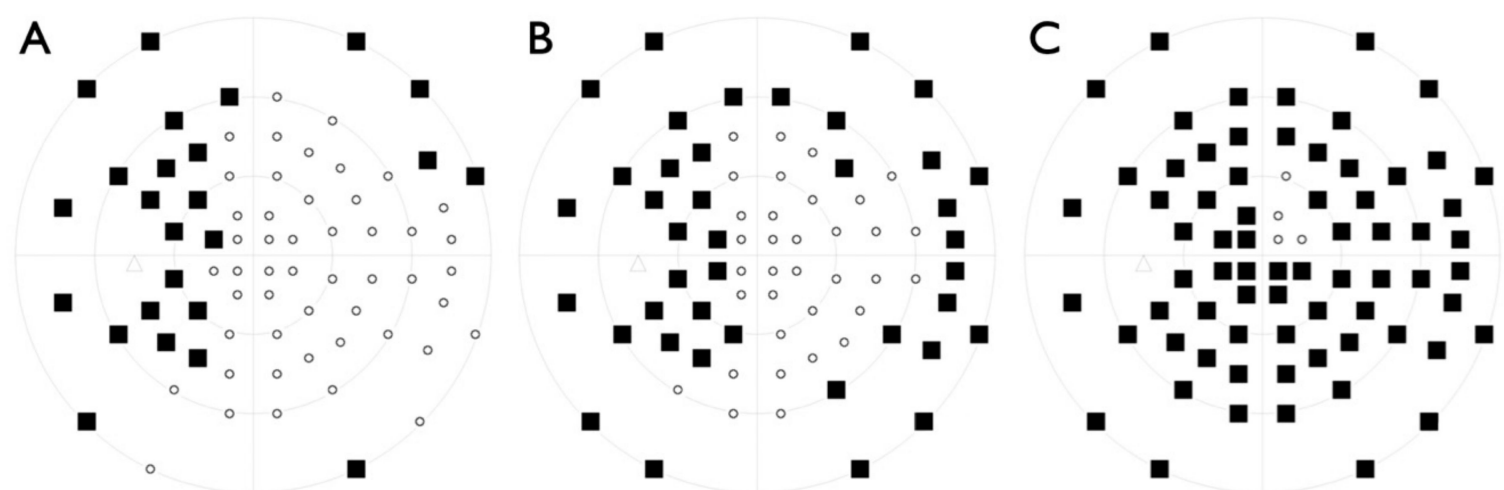

口

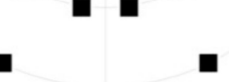

Figure 7. Visual field progression in patient IV:2 from family BD 35 between (A) 51, (B) 56 and (C) 60 years of age. 

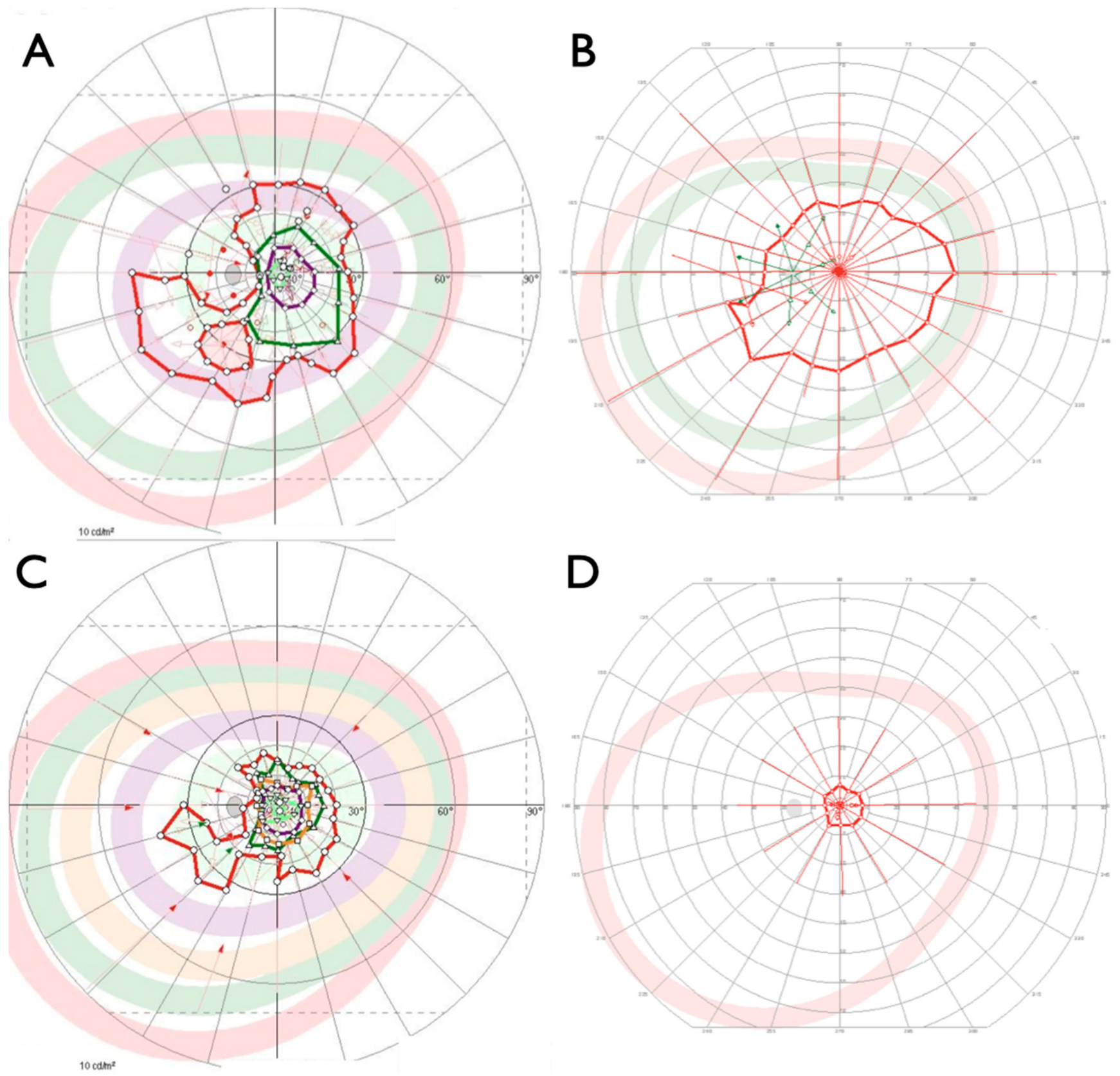

Figure 8. Visual fields in patient IV:1 (A), patient IV:2 (B) and patient IV:3 from family ADRP 386 at 50 (C) and 56 years of age (D). Please note that visual fields were obtained with different software and therefore cannot be displayed with the same look. Degrees are scaled similarly for all images.

In patient IV:2 from family BD 35, full-field ERG was reported as slightly abnormal with an unspecified method at 18 years of age and the EOG showed a severely reduced light rise. At 38 and 42 years of age, ERG amplitudes according to ISCEV standards were markedly reduced. At 50 years of age, only residual responses were recordable in the ERG. Similarly, no measurable or small residual responses could be recorded in the father (patient III:2) as well as in all patients of family ADRP 386 between 50 to 58 years of age. The mfERG, recorded in three patients, showed centrally preserved responses with reduced amplitude but normal implicit time corresponding to areas with preserved retina and absent responses in atrophic areas. 


\subsection{Identification of a Novel Missense Variant in C1QTNF5}

The self-reported family history of family BD 35 was indicative of an autosomal dominant pattern of inheritance for family BD 35 while it was consistent with an autosomal dominant inheritance mode for family ADRP 386 with affected individuals in four consecutive generations.

Patients III:2 and IV:2 from family BD 35 as well as patients IV:1 and IV:3 from family ADRP 386 underwent diagnostic genetic testing by whole genome sequencing. Putative pathogenic variants were only identified in the C1QTNF5 gene, namely a novel missense variant (c.538C > G/p.(Q180E)), which was found in heterozygous state in all family members that were available for genetic testing (Figure 2). The variant is absent from the population database gnomAD (https:/ / gnomad.broadinstitute.org/), indicating that it is very rare. In silico predictions of the p.(Q180E) variant using various online tools were discordant. It was predicted to be possibly damaging (PolyPhen2), disease causing (MutationTaster), neutral (PROVEAN) or tolerated (SIFT) (Appendix A Table A1). Sequence alignment of C1QTNF5 and orthologous proteins in other species showed that p.(Q180E) is fully conserved in 176 vertebrate species (Appendix A Table A2). Accordingly, the high level of evolutionary conservation is reflected by high scores obtained with PhyloP, CADD and FATHMM (Appendix A Table A1).

As far as could be established from the self-reported family histories the two families are either not or very distantly related (i.e., not being aware of their relatedness). In order to distinguish between the alternative hypotheses of recurrent mutation and identity by descent, we established haplotypes using SNP data obtained by whole genome sequencing. In addition, two annotated microsatellites in the vicinity of C1QTNF5 were analyzed. Appendix A Figure A1 shows that p.(Q180E) is associated with the same haplotype on all disease alleles analyzed. This is consistent with the mutant allele being identical by descent.

Patients of both families presented with similar clinical findings and segregated the same variant. This suggested an association with the novel p.(Q180E) variant with adGALCD.

2.3. Molecular Modeling of C1QTNF5 and Analysis of the Structural and Functional Effects of the Missense Mutation p.(Q180E)

The autosomal dominant nature of adGALCD and LORD implies that, in the pool of expressed C1QTNF5 proteins, half of the molecules will carry the Q180E mutation, whereas the other half will be unaffected (wild-type, WT). This fact, together with the supramolecular organization of C1QTNF5 (Figure 1) opens up a very complex scenario, in which both WT and mutated protomers can form assemblies, whose protomers can either be mutated or not. We considered all these possibilities in our molecular modeling analyses.

The Q180E amino acid substitution could in first instance perturb the stability of each C1QTNF5 protomer. To evaluate such a possibility, Gln180 was replaced with the negatively charged Glu. The apparent change in free energy of folding with respect to the WT $\left(\Delta \Delta \mathrm{G}_{\mathrm{f}}^{\mathrm{app}}\right)$ was calculated for the single protomer, resulting in a $2.56 \mathrm{kcal} / \mathrm{mol}$ destabilization. Replacement of superficial protein charges may perturb long-range electrostatics in proteins, with significant effects on protein stability [20]. A first effect of the Q180E mutation could therefore be the destabilization of the tertiary structure of C1QTNF5.

Residue Q180 is the last residue of $\beta$-strand E (Figure 1B) and it is located between the hydrophobic plateau and the hydrophobic "zipper" box. The analysis of the protomer surface highlighted that residue Q180 is fundamental for the reciprocal interaction among the three protomers constituting the globular head of C1QTNF5. Indeed, the aggregation score provided by AggScore (11052) for residue Q180 resulted to be the highest value reported for the entire protein sequence, suggesting that mutations involving Q180 may have a detrimental effect on the association of the trimeric globular head and its stability. Considering the whole globular head, the substitution of a polar uncharged residue with a negatively charged residue close to the highly hydrophobic "zipper" interface altered the partial charge distribution and therefore the electrostatic potential on the protomer 
surface (Figure 9A,C). Such alteration resulted in an electrostatic repulsion between the negative charges of two interacting protomers (Figure 9B,D), affecting both the stability of the complex $\left(\Delta \Delta \mathrm{G}_{\mathrm{f}}\right.$ app $=30.5 \pm 1.0 \mathrm{kcal} / \mathrm{mol}$, Table 3) and the affinity of the protomers for one another $\Delta \Delta \mathrm{G}_{\mathrm{b}}$ app $=12.2 \pm 5.5 \mathrm{kcal} / \mathrm{mol}$, Table 3). On the other hand, the presence of two or even three mutations within the same trimer (Figure 9B,D) further increased the electrostatic repulsion, thus causing a destabilization of the complex $\left(\Delta \Delta \mathrm{G}_{\mathrm{f}}\right.$ app $=64.8 \pm 1.6$ and $101.12 \pm 0.04 \mathrm{kcal} / \mathrm{mol}$, respectively, Table 3) and a decrease in affinity of the protomers $\left(\Delta \Delta \mathrm{G}_{\mathrm{b}}{ }^{\text {app }}=27.7 \pm 6.6\right.$ and $44.7 \pm 1.4 \mathrm{kcal} / \mathrm{mol}$, respectively, Table 3$)$. It is worth noting that the contribution of coulombic repulsion to the apparent binding free energy among protomers in the trimer impacted both affinity and stability. On the contrary, the contribution of solvation of the mutated trimer decreased the apparent affinity of the protomers $\left(\Delta \Delta \mathrm{G}_{\mathrm{b}}\right.$ app $\mathrm{S}=9.4 \pm 1.2 \mathrm{kcal} / \mathrm{mol}$, Table 4$)$ but it was found to increase the stability of the ternary complex $\left(\Delta \Delta \mathrm{G}_{\mathrm{f}}\right.$ app $\mathrm{S}=-45.5 \pm 1.2 \mathrm{kcal} / \mathrm{mol}$, Table 4$)$.
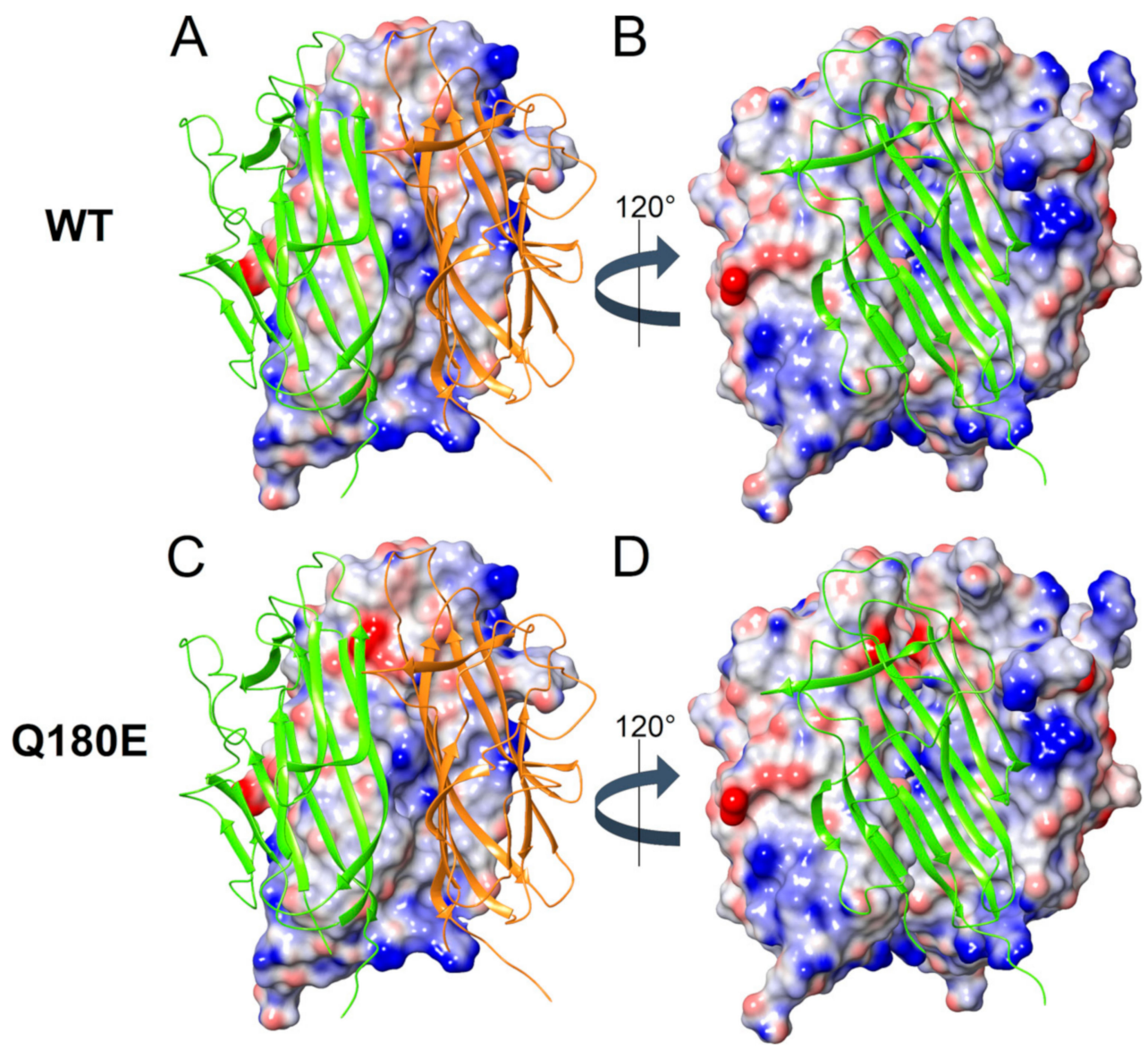

Figure 9. Electrostatic potential mapped on the molecular surface of a C1QTNF5 wild-type (WT) (A,B) and Q180E (C,D) homozygous trimer. Protein structure is shown in cartoon, protomer B is colored in orange, protomer $C$ in green. The molecular surface of protomers A and B is colored in a blue-to-red scale from -0.3 to $0.3 \mathrm{kT} / \mathrm{e}$. (A,C) Electrostatic potential of protomer A. (B,C) Electrostatic potential of protomers A and B, protein view is rotated by $120^{\circ}$ counterclockwise along the symmetry axis.

In summary, the Q180E substitution was predicted to generate a significant electrostatic repulsion among the protomers forming up a globular head, whose effects could propagate at longer distance, considering the significantly changed electrostatic potential generated by a trimer (Figure 10), which could affect the recognition between two adjacent globular heads approaching each other. Indeed, on a larger scale, the Gln-to-Glu substitution in position 180 also affected the interaction between adjacent globular heads belonging to different cells, as shown by the positive $\Delta \Delta \mathrm{G}_{\mathrm{b}}$ app and $\Delta \Delta \mathrm{G}_{\mathrm{f}}$ app shown by 
the mutants (Table 3). Similar to the interaction among protomers of the same globular head (Figure 10), the top-to-top interaction between globular heads was increasingly destabilized by the Q180E mutation proportionally to the number of mutations present in the two trimers. Indeed, the remapping of electrostatic potential involving globular heads' interface resulted in an increase of $\Delta \Delta \mathrm{G}_{\mathrm{b}}$ app from $9.0 \mathrm{kcal} / \mathrm{mol}$ in the presence of 1 protomer carrying the mutation to approximately $60 \mathrm{kcal} / \mathrm{mol}$ in the presence of the homozygous variant (Table 3), while $\Delta \Delta \mathrm{G}_{\mathrm{f}}$ app increased from 26.7 to $187.8 \mathrm{kcal} / \mathrm{mol}$ under the same conditions (Table 3). Interestingly, the presence of mutations was favorable in terms of electrostatic interactions between the two globular heads from both the affinity and stability standpoints, as shown by the negative $\Delta \Delta \mathrm{G}$ values for both binding and folding $\left(\Delta \Delta \mathrm{G}_{\mathrm{b}}\right.$ app $\mathrm{C}$ and $\Delta \Delta \mathrm{G}_{\mathrm{f}}$ app $\mathrm{C}$ columns, Table 3). On the other hand, such positive coulombic contribution was counterbalanced by the larger, unfavorable increase in $\Delta \Delta \mathrm{G}$ of solvation $\left(\Delta \Delta \mathrm{G}_{\mathrm{b}}\right.$ app $\mathrm{S}$ and $\Delta \Delta \mathrm{G}_{\mathrm{f}}$ app $\mathrm{S}$ columns, Table 3) resulting from the addition of a negatively charged residue to a highly hydrophobic patch.

Table 3. Effects of the number of Q180E-mutated protomers on the relative affinity $\left(\Delta \Delta \mathrm{G}_{\mathrm{b}}\right.$ app $)$ and stability $\left(\Delta \Delta \mathrm{G}_{\mathrm{f}}^{\text {app }}\right)$ of the globular heads constituted by three protomers (Protomer-protomer) and of the interaction between globular heads (Trimer-trimer). $\Delta \Delta \mathrm{G}$ values are reported as average \pm standard deviation of $[n]$ possible combinations of $\mathrm{WT} /$ mutant complexes.

\begin{tabular}{|c|c|c|c|c|c|c|}
\hline $\begin{array}{c}\text { Number of } \\
\text { Mutations }[n]\end{array}$ & $\begin{array}{c}\Delta \Delta \mathrm{G}_{\mathrm{b}}^{\mathrm{app}} \\
(\mathrm{kcal} / \mathrm{mol})\end{array}$ & $\begin{array}{c}\Delta \Delta \mathrm{G}_{\mathrm{b}}{ }^{\text {app }} \mathrm{C}^{+} \\
(\mathrm{kcal} / \mathrm{mol})\end{array}$ & $\begin{array}{c}\Delta \Delta \mathrm{G}_{\mathrm{b}} \text { app } \mathrm{S} \\
(\mathrm{kcal} / \mathrm{mol})\end{array}$ & $\begin{array}{c}\Delta \Delta \mathrm{G}_{\mathrm{f}}^{\mathrm{app}} \\
(\mathrm{kcal} / \mathrm{mol})\end{array}$ & $\begin{array}{c}\Delta \Delta \mathrm{G}_{\mathrm{f}}^{\text {app } \mathrm{C}^{+}} \\
(\mathrm{kcal} / \mathrm{mol})\end{array}$ & $\begin{array}{c}\Delta \Delta \mathrm{G}_{\mathrm{f}}^{\mathrm{app}} \mathrm{S} \text { * } \\
(\mathrm{kcal} / \mathrm{mol})\end{array}$ \\
\hline \multicolumn{7}{|c|}{ Protomer-protomer } \\
\hline 1 mut [9] & $12.2 \pm 5.5$ & $-0.43 \pm 0.06$ & $12.9 \pm 4.7$ & $30.5 \pm 1.0$ & $44.7 \pm 2.6$ & $-9.0 \pm 4.8$ \\
\hline 2 mut [9] & $27.7 \pm 6.6$ & $11.4 \pm 9.8$ & $16.5 \pm 5.2$ & $64.8 \pm 1.6$ & $95.3 \pm 9.8$ & $-24.1 \pm 5.2$ \\
\hline 3 mut [3] & $44.7 \pm 1.4$ & $35.3 \pm 1.9$ & $9.4 \pm 1.2$ & $101.12 \pm 0.04$ & $151.8 \pm 1.9$ & $-45.5 \pm 1.2$ \\
\hline \multicolumn{7}{|c|}{ Trimer-trimer } \\
\hline 1 mut [6] & $9.0 \pm 9.8$ & $-42.9 \pm 5.5$ & $52.4 \pm 12.3$ & $26.7 \pm 2.8$ & $-90.7 \pm 13.6$ & $127.4 \pm 25.8$ \\
\hline 2 mut [15] & $18.6 \pm 12.4$ & $-83.4 \pm 6.7$ & $103.2 \pm 15.4$ & $55.6 \pm 4.4$ & $-173.7 \pm 18.7$ & $248.5 \pm 32.7$ \\
\hline 3 mut [20] & $28.6 \pm 13.6$ & $-121.1 \pm 7.1$ & $151.6 \pm 16.9$ & $86.3 \pm 4.9$ & $-249.1 \pm 20.3$ & $362.9 \pm 35.6$ \\
\hline 4 mut [15] & $38.9 \pm 13.2$ & $-156.3 \pm 7.1$ & $197.8 \pm 16.2$ & $118.8 \pm 4.7$ & $-316.7 \pm 18.1$ & $470.8 \pm 34.3$ \\
\hline 5 mut [6] & $49.5 \pm 11.2$ & $-190.1 \pm 5.6$ & $242.9 \pm 13.0$ & $152.7 \pm 4.2$ & $-376.7 \pm 12.3$ & $572.0 \pm 28.4$ \\
\hline 6 mut [1] & 60.0 & -221.7 & 285.9 & 187.8 & -429.0 & 666.3 \\
\hline
\end{tabular}

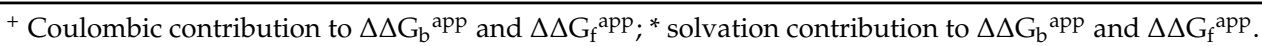

Table 4. Phenotypes of C1QTNF5 associated disorders: adGALCD and LORD.

\begin{tabular}{|c|c|c|}
\hline & adGALCD & LORD \\
\hline C1QTNF5 & c.538C >G, p.(Q180E) & $\begin{array}{l}\text { c. } 489 \mathrm{C}>\mathrm{G}, \mathrm{p} .(\mathrm{S} 163 \mathrm{R}) \\
\text { c. } 489 \mathrm{C}>\mathrm{A}, \mathrm{p} .(\mathrm{S} 163 \mathrm{R}) \\
\text { c. } 556 \mathrm{C}>\mathrm{T}, \mathrm{p} .(\mathrm{P} 186 \mathrm{~S}) \\
\text { c. } 562 \mathrm{C}>\mathrm{A}, \mathrm{p} .(\mathrm{P} 188 \mathrm{~W}) \\
\text { c. } 569 \mathrm{C}>\mathrm{G}, \mathrm{p} .(\mathrm{S} 190 \mathrm{~W}) \\
\text { c. } 646 \mathrm{G}>\mathrm{T}, \mathrm{p} .(\mathrm{G} 216 \mathrm{C})\end{array}$ \\
\hline Age at onset symptoms & 40 years & $40-50$ years \\
\hline Initial functional deficits & $\begin{array}{l}\text { Problems with adaption in the dark, } \\
\text { night blindness }\end{array}$ & $\begin{array}{l}\text { Problems with adaption in the dark, } \\
\text { night blindness }\end{array}$ \\
\hline Age at onset of retinal alterations & 18-24 years & $44-50$ years \\
\hline Area of onset & Peripheral and peripapillary atrophy & Midperipheral, temporal to the macula \\
\hline Pseudodrusen-like changes & No & Yes \\
\hline Sub-RPE deposits & No & Yes \\
\hline Choroidal atrophy & Large and confluent, sharply demarcated & $\begin{array}{l}\text { Scalloped beginning temporal of the } \\
\text { macula in areas with previous } \\
\text { pseudodrusen, irregular borders }\end{array}$ \\
\hline
\end{tabular}


Table 4. Cont.

\begin{tabular}{ccc}
\hline & adGALCD & LORD \\
\hline Pigmentation & No or minimal & Moderate to marked \\
\hline Choroidal neovascularization & Not observed & Frequent during progression \\
\hline FAF & $\begin{array}{c}\text { Secondary to choroidal } \\
\text { neovascularization }\end{array}$ \\
\hline OCT & $\begin{array}{c}\text { Large, sharply demarcated areas of } \\
\text { absent/severely reduced FAF }\end{array}$ & $\begin{array}{c}\text { Fleck-like irregular or scalloped } \\
\text { midperipheral loss bordered by increased } \\
\text { FAF, irregular in macular lesions }\end{array}$ \\
\hline ERG & $\begin{array}{c}\text { No deposits, absence of RPE and } \\
\text { photoreceptors in affected areas }\end{array}$ & $\begin{array}{c}\text { Subretinal deposits, irregular } \\
\text { photoreceptor loss }\end{array}$ \\
\hline mfERG & $\begin{array}{c}\text { Markedly reduced at age 38, residual or } \\
\text { not measurable responses at age }>50 \\
\text { years }\end{array}$ & $\begin{array}{c}\text { Normal or well-preserved ERG up to } \\
60-67 \text { years of age }\end{array}$ \\
\hline Anterior segment & $\begin{array}{c}\text { Reduced amplitude, normal implicit time } \\
\text { in preserved areas, no response in } \\
\text { affected areas }\end{array}$ & $\begin{array}{c}\text { Not reported } \\
\text { Normal }\end{array}$ \\
\hline
\end{tabular}

adGALCD: autosomal dominant gyrate atrophy-like choroidal dystrophy, LORD: late-onset retinal degeneration, RPE: retinal pigment epithelium, FAF: fundus autofluorescence, OCT: optical coherence tomography, ERG: full-field electroretinography, mfERG: multifocal ERG
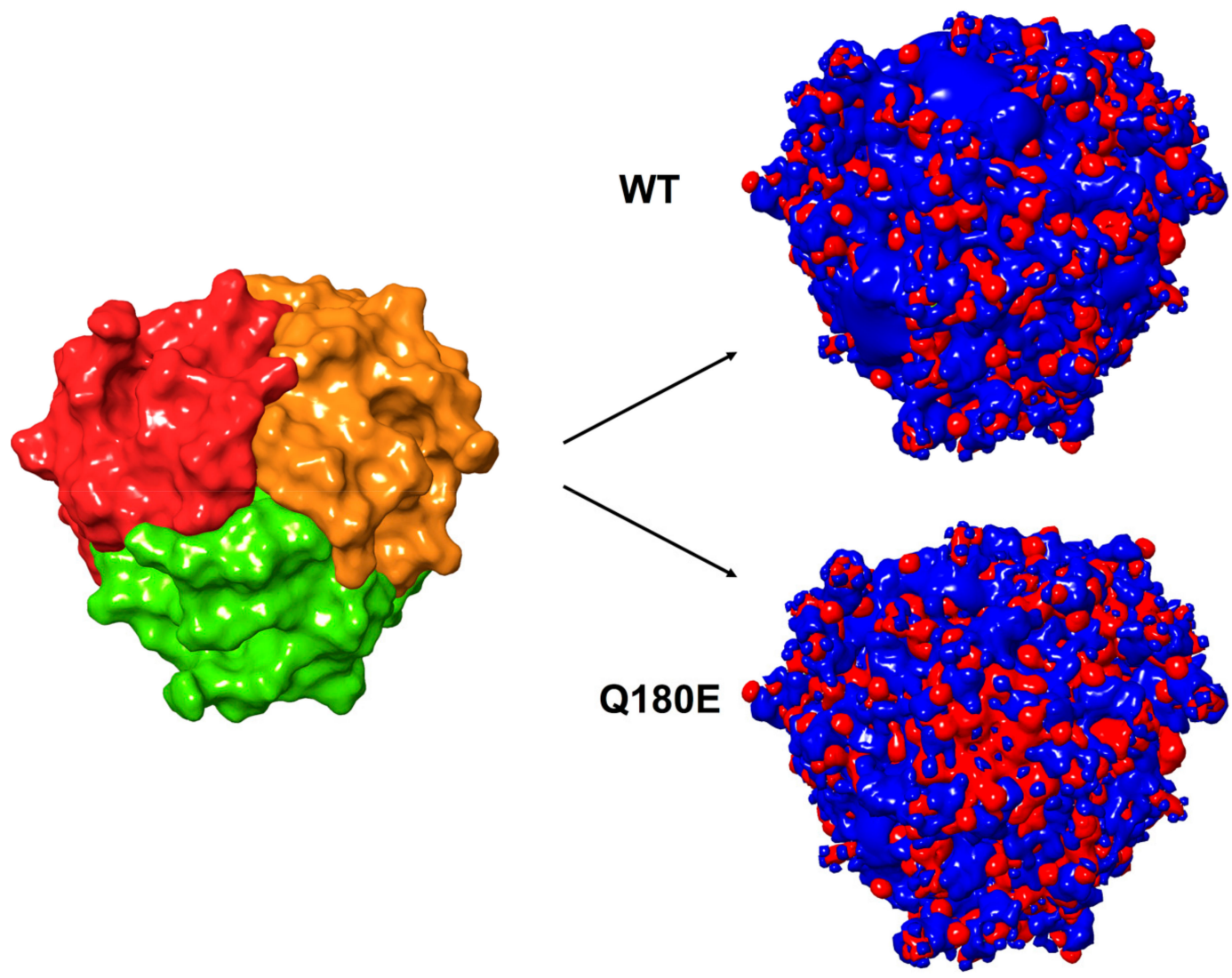

Figure 10. Electrostatic isopotential surfaces of WT and Q180E homozygous C1QTNF5 trimers forming a single globular head show unfavorable electrostatic contributions to association in the case of mutated protomers. The top view of the molecular surface of protomers A, B and C (colored in red, orange and green, respectively) is shown to clarify the relative orientation of each protomer. The electrostatic isopotential surfaces corresponding to $-10 \mathrm{kT} / \mathrm{e}$ and $10 \mathrm{kT} / \mathrm{e}$ are shown in red and blue, respectively. 


\section{Discussion}

Autosomal dominant gyrate atrophy-like choroidal dystrophy (adGALCD) appears to be a distinct entity that has been described so far in three families. Two of them are included in this manuscript, while images consistent with the ocular phenotype have already been reported for another family without detailed information [6]. As all three families were observed in Germany, it might well be that they are all related. This assumption is supported by haplotype analysis for the two families reported in the present study.

Compared to the clearly defined entities of gyrate atrophy and choroideremia, the onset is later and the rate of progression in adGALCD is slower, e.g., reading ability may be preserved up to 70 years of age. The chorioretinal lesions are more clearly demarcated compared to choroideremia. In contrast to gyrate atrophy, early onset of cataract formation and hyperornithinemia were not observed, and cystoid macular edema was only seen in one patient.

The finding of a putative pathogenic variant in the C1QTNF5 gene supports the inclusion of adGALCD into the spectrum of LORD. However, the clinical findings differ in several aspects between adGALCD and LORD (Table 4). The onset of retinal alterations is earlier and more peripheral in adGALCD compared to LORD [21-26]. In contrast to adGALCD with peripheral retinal changes present at least at the end of the second decade of life, patients with stage 1 LORD are reported to show a normal retina until 40 years of age, while long anterior lens zonules and iris atrophy may already by present $[26,27]$. The peripheral lesions in adGALCD are associated with early peripheral visual field loss, while the peripheral visual fields remain intact in LORD even in progressed stages [25]. Characteristic findings of stage $2 \mathrm{LORD}$ are subretinal deposits which present in a pseudodrusen-like pattern with sub-RPE material and a thickening between RPE and Bruch membrane in the OCT $[9,11,21-23,28-30]$. These pseudodrusen-like lesions first develop in the temporal middle periphery progressing to scalloped chorioretinal atrophy as well as pigmentary changes, all of which were not observed in the adGALCD families. Although scalloped chorioretinal atrophic lesions have been observed in adGALCD and LORD [4,9,13,21-25,31-34], scalloped lesions in LORD are located in the mid-periphery and are much smaller in size compared to those observed in the patients in the present and previous study [7]. Stage 3 LORD is characterized by atrophic macular alterations or choroidal neovascularizations $[11,24,27,34,35]$, whereas in adGALCD neovascular lesions were not observed and the fovea was preserved until the final stage. As such, the phenotype in the families presented in this study much more resembles gyrate atrophy than LORD. Distinct characteristics of LORD in FAF and OCT were not observed in adGALCD: no sub-RPE deposits in the OCT and no structural alterations prior to RPE loss in the FAF were detected $[25,26,29,33,36]$.

In addition, retinal function was earlier and more severely affected in adGALCD as indicated by earlier and markedly reduced ERG and multifocal ERG responses. Normal or well-preserved ERG has been reported up to 60-67 years of age in LORD [23,33,37].

A frequent additional finding in LORD are long anterior lens zonules $[12,22,24,25,28$, $32,38,39]$, although they are not present in all LORD patients [13] and may also occur in the absence of LORD [40]. Long anterior lens zonules were not observed in the patients in this study. In addition, no problems during cataract surgery were observed or reported in contrast to LORD [41].

A similarity between adGALCD and LORD is the development of night blindness at about 40 years of age in most patients [26]. This appears unexplained for both disorders, while at that age still sufficient rod-rich areas along the vascular arcades appear to be structurally normal in the patients presented here as well as in LORD. As previously suggested [26], C1QTNF5 gene variants may affect rod function with an additional mechanism which still has to be defined.

The C1QTNF5 gene product is present in the lateral and basal membrane of retinal pigment epithelial cells and the ciliary body [42]. It interacts with HTRA1 in mice and affects extracellular matrix turnover, which might explain the development of subretinal deposits in LORD [43-45]. Following the resolution of X-ray structures of the globular 
domain of C1QTNF5 [16,18], molecular models were built to explain the mechanism of C1QTNF5-mediated cell adhesion among RPE cells and RPE-Bruch membrane. The typical bouquet-like octadecameric organization of C1QTNF5 ensuring the appropriate scaffold for cell-cell communication can be reached only by specific molecular recognition between C1QTNF5 subunits within the same and with surrounding globular head domains. Point mutations of key amino acids involved in the protein-protein recognition process can therefore lead to destabilization of these supramolecular assemblies. In case of autosomal dominant diseases, homo- and hetero-complexes can be formed by the expressed WT and mutant proteins, thus generating a complex molecular scenario that has emerged recently, with specific effects depending on the nature of the complex [46,47]. In the case of C1QTNF5, the scenario is extremely complex, with up to 64 possible assemblies between wild-type and individually mutated protomers. As a general conclusion, our modeling study predicts that, independently on the number of mutated protomers, the p.(Q180E) substitution will perturb both the stability of the globular heads and the recognition between adjacent trimers. This would result in a perturbation of the molecular scaffold linking to adjacent cells, ultimately disrupting the native cell-adhesion mechanisms.

\section{Materials and Methods}

\subsection{Patient Enrollment and Retrieval of Blood Samples}

Patients were recruited and clinically examined either at the Eye Hospital of the University of Tübingen (family ADRP 386) or at the AugenZentrum Siegburg (family BD 35). Genomic DNA of patients was extracted from peripheral blood using standard protocols. Samples from all patients were recruited in accordance with the principles of the Declaration of Helsinki and were obtained with written informed consent accompanying the patients' samples. The study was approved by the institutional review board of the Ethics Committee of the University Hospital of Tübingen under the study numbers $349 / 2003 \mathrm{~V}$ and $116 / 2015 \mathrm{BO}$.

\subsection{Clinical Examination}

Family BD 35 included four members who have been examined, three of them affected males including the father and both of his sons (see pedigree depicted in Figure 2). Details of these examinations have been reported previously [7]. The father (III:2) was lost to follow-up due to stroke-associated death and one son (IV:2) due to a brain tumor. The second son (IV:2) was re-examined at different time intervals between 38 to 63 years of age. In addition to basic ophthalmologic examination, he underwent visual field testing, fullfield electroretinography (ERG) and multifocal ERG (mfERG) recording, wide-angle fundus autofluorescence (FAF), near-infrared autofluorescence (NIA), spectral domain OCT (OCT) examinations and OCT-angiography. Family ADRP 386 comprises three siblings. All three siblings underwent in addition to basic ophthalmologic examination visual field testing, ERG and mfERG recording, FAF and OCT examination. Please note that the phenotype in family ADRP 386 was initially described as autosomal dominant retinitis pigmentosa (ADRP) but that the original family ID was kept after refinement of the clinical diagnosis based on examination of more family members and longer follow-up.

Electrophysiologic examinations and non-invasive retinal imaging were obtained as described previously after medical dilatation of the pupil [48,49]. Full-field ERG and mfERG were measured according to the most recent ISCEV standards [50,51] at the time of recording. FAF and NIA were obtained with a confocal scanning laser ophthalmoscope (Heidelberg Retina Angiograph 2, Heidelberg Engineering, Heidelberg, Germany) using $30^{\circ}$ and $50^{\circ}$ lenses. Volume and single scan SD-OCT as well as OCT-angiography were performed with a Spectralis OCT (Heidelberg Engineering, Heidelberg, Germany).

\subsection{Diagnostic Genetic Testing}

Patients III:2 and IV:2 from family BD 35 and patients IV:1 and IV:3 from family ADRP 386 underwent diagnostic genetic testing by means of whole genome sequencing. Details 
of sequencing and variant classification have been described previously [52]. Segregation analysis in family members was performed using conventional Sanger sequencing.

\subsection{Haplotype Analysis}

Haplotype analysis was performed in all available family members by genotyping two microsatellites in the vicinity of C1QTNF5 (D11S614 and D11S4129). Primers for microsatellite amplification were as follows: D11S614-forward: 5'-ACAGACCCACCAGGACTAT-3', D11S614-reverse: 5'-CCCGGATGTCTGCAAGGTGG-3'; D11S4129-forward: 5' -ACAGCGA CCACATCTCCTGC-3', D11S4129-reverse: 5'-GGCCACTGCCCTTACCATCA-3'. Genotyping of microsatellites was performed as described previously [53]. Extended haplotype analysis was performed in patients III:2 and IV:2 from family BD 35 and patients IV:1 and IV:3 from family ADRP 386 using informative genotype data of 41 SNPs spanning a physical region of $2 \mathrm{Mb}$ interval surrounding C1QTNF5. Genotypes were considered informative if they could be unambiguously assigned to a haplotype. The genotype data were obtained from the whole genome sequencing datasets.

\subsection{In Silico Predictions of Pathogenicity}

Online prediction tools PolyPhen2 (http://genetics.bwh.harvard.edu/pph2/), MutationTaster (http:/ / www.mutationtaster.org/), and PROVEAN and SIFT (http:/ / provean. jcvi.org/genome_submit_2.php), were used to predict the impact of the p.(Q180E) substitution on C1QTNF5. PhyloP, CADD and FATHMM-MKL scores were retrieved from the megSAP pipeline (https://github.com/imgag/megSAP). Orthologous gene sequences were downloaded from NCBI (https: / / www.ncbi.nlm.nih.gov/), and amino acid sequences aligned using ClustalW2 (https://www.ebi.ac.uk/Tools/msa/clustalw2/).

4.6. Molecular Modeling of C1QTNF5 Protein Structure and Analysis of the p.(Q180E) Effects on Stability and Affinity

All molecular modeling analyses were performed within the environment of the chemical simulation software Maestro/Bioluminate (Schroedinger, New York, USA). Human C1QTNF5 trimer was modeled using as the starting structure the PDB file with entry 4 F3J [16], which provided the highest resolution (1.34 $\AA$ ) among the available structures, as well as the symmetric operators for reconstituting the trimeric biological unit. The hexameric assemble of two globular heads was built superimposing the trimers to the top-to-top interacting protomers of PDB file 4NN0 (resolution $1.42 \AA$ ) [18]. The trimeric globular heads were reconstituted using the symmetric operators previously included in PDB file 4F3J [16]. This allowed us to evaluate the effects of the pathogenetic point mutation within each individual protomer making up a globular head (trimer), as well as a couple of globular heads from two different cells, interacting with each other (interacting trimers, Figure 1C,D).

Protein structures were prepared according to the pipeline of the Protein Preparation tool, briefly consisting of the assignment of bond orders using Chemical Components Dictionary database (www.pdb.org, wwPDB Foundation, Piscataway NJ, USA), addition of $\mathrm{H}$ atoms, selection of the most probable rotamer and deletion of water molecules closer than $3.5 \AA$ only to other water molecules. Structure refinement included sampling of water orientation, usage of crystal symmetry to optimize H-bonds with the other protomers and prediction of the protonation states of ionizable residues at $\mathrm{pH} 7.5$ by PROPKA prior to $\mathrm{H}$-bond assignment and optimization. Finally, protein structure was minimized using the OPLS3e forcefield (Schroedinger, New York, NY, USA) until the Root-Mean Square Displacement of the heavy-atom reached $0.3 \AA$.

The role of residue Gln180 (in the WT protein) in protomer association was investigated by the "Protein Surface Analysis" tool. A well-performing index based on the analysis of the distribution of hydrophobic and electrostatic patches on the surface of the protein, the AggScore index [54], was calculated to estimate aggregation propensity of the protomer. 
The electrostatic potential surface was calculated by the "Poisson-Boltzmann Electrostatic Potential Surface" tool, by setting solute dielectric constant to 1, solvent dielectric constant to 80 , solvent radius to $1.4 \AA$, temperature to $298 \mathrm{~K}$, grid extension to $5 \AA$.

The "Residue Scanning" tool was employed to introduce the p.(Q180E) mutation in any combination of both the three protomers constituting a globular domain and the two interacting globular domains, thus resulting in 7 and 63 combinations, respectively. Each mutagenized structure was subjected to automatic selection of the most probable rotamer and energy minimization using the same parameters as those employed for the wild-type (WT) model.

The Molecular Mechanics/Generalized Born and Surface Area Continuum Solvation (MM/GBSA) method was used to predict the effects of residue mutation on protomer stability and affinity, in terms of relative changes compared to the WT, by using the specific thermodynamic cycle. It should be noticed that the free energy computed by the method is based on the MM force field without explicit contributions from conformational changes, therefore the obtained free energy values $\left(\Delta \Delta \mathrm{G}^{\text {app }}\right.$ in Table 2 , expressed in $\mathrm{kcal} / \mathrm{mol}$ ) should be taken as "apparent" values and considered as approximate indexes, which are useful in comparisons, rather than rigorously defined thermodynamic quantities. Protomerprotomer affinity was calculated for each of the three protomers against the other two protomers. The resulting 21 combinations were pooled for the number of mutations present in the trimeric assembly and the variations in the apparent binding affinity $\left(\Delta \Delta \mathrm{G}_{\mathrm{b}}\right.$ app $)$ and apparent stabilities $\left(\Delta \Delta \mathrm{G}_{\mathrm{f}}^{\text {app }}\right)$. Presented in Table 3 are the average \pm standard deviation of the respective group, whose size is also reported. Trimer-trimer affinity was calculated between the two globular heads, the 63 combinations obtained by "Residue Scanning" were grouped by the number of variants in the hexameric assembly with the same approach as that employed for protomer-protomer affinity. The contribution of electrostatics and solvation to the relative $\Delta \Delta \mathrm{G}^{\text {app }}$ values for both binding and stability was specifically reported in Table 3 and discussed.

Author Contributions: Conceptualization, U.K., N.W. and D.D.; data curation, U.K., N.W., V.M. and D.D.; formal analysis, N.W., V.M. and D.D.; funding acquisition, U.K. and D.D. investigation, U.K., N.W., S.W., G.F., S.D., F.K., P.M., K.S., V.M. and D.D.; methodology, U.K., N.W. and D.D.; project administration, U.K. and N.W.; resources, U.K., N.W., F.K., P.M. and D.D.; software, V.M. and D.D.; supervision, U.K. and N.W.; validation, U.K., N.W., S.W., G.F., S.D., P.M., K.S. and D.D.; visualization, U.K., N.W. and D.D.; writing—original draft, U.K. and N.W.; writing—review and editing, U.K., N.W. and D.D. All authors have read and agreed to the published version of the manuscript.

Funding: This research was partly funded by a grant from the University of Verona (Joint Project 2018 JPVR184ZZ5 to D.D.).

Institutional Review Board Statement: The study was approved by the institutional review board of the Ethics Committee of the University Hospital of Tübingen under the study numbers 349/2003V and 116/2015BO2.

Informed Consent Statement: Samples from all patients were recruited in accordance with the principles of the Declaration of Helsinki and were obtained with written informed consent accompanying the patients' samples.

Data Availability Statement: The data presented in this study are available on request from the corresponding author. The data are not publicly available due to health system data regulations.

Conflicts of Interest: The authors declare no conflict of interest. The funders had no role in the design of the study; in the collection, analyses, or interpretation of data; in the writing of the manuscript, or in the decision to publish the results. 


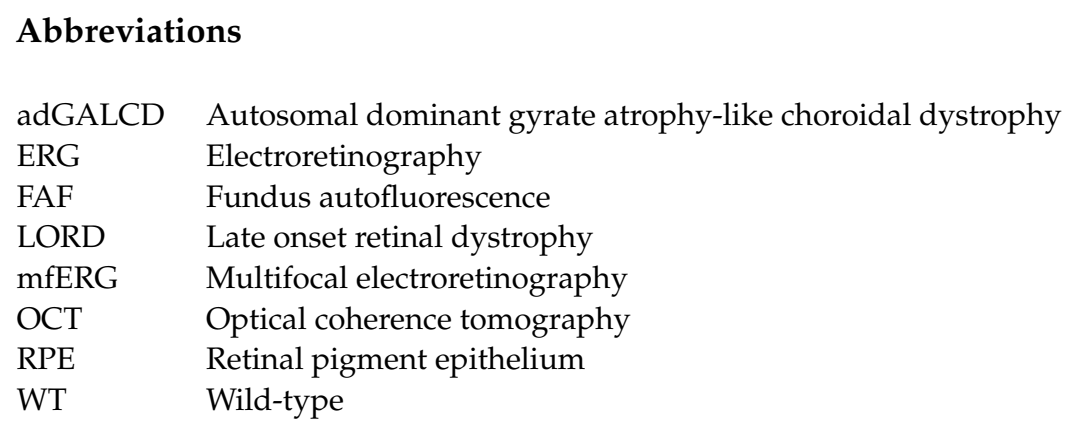

\section{Appendix A}

Table A1. In silico predictions of different pathogenicity-computation methods for the p.(Q180E) variant.

\begin{tabular}{ccccccc}
\hline PolyPhen2 & MutationTaster & PROVEAN & SIFT & phyloP & CADD & FATHMM-MKL \\
\hline $\begin{array}{c}\text { Possibly damaging } \\
(0.692)\end{array}$ & $\begin{array}{c}\text { Disease causing } \\
(0.999)\end{array}$ & $\begin{array}{c}\text { Neutral } \\
(0.38)\end{array}$ & $\begin{array}{c}\text { Tolerated } \\
(0.254)\end{array}$ & 9.071 & 25.00 & 0.98 \\
\hline
\end{tabular}

Table A2. Sequence conservation of the p.(Q180E) variant in orthologous C1QTNF5 protein sequences.

\begin{tabular}{|c|c|}
\hline Species & Amino Acid Snippet \\
\hline Homo sapiens & 178 FFQFFGGWPKPASLSGGAMVR 198 \\
\hline Acanthisitta chloris & 178 FFQYYGNWPKPTSLSGGTLVR 198 \\
\hline Acinonyx jubatus & 92 FFQFFGGWPKPASLSGGAMVR 112 \\
\hline Ailuropoda melanoleuca & 88 FFQFFGGWPKPASLSGGAMVR 108 \\
\hline Alligator mississippiensis & 176 FFQFYGNWPKPTSLSGGSLVR 196 \\
\hline Alligator sinensis & 176 FFQFYGNWPKPTSLSGGSLVR 196 \\
\hline Anas platyrhynchos & 353 FFQYYGNWPKPTSLSGGALVR 373 \\
\hline Anolis carolinensis & 180 FFQFYGNWPKPTSLSGGALVR 200 \\
\hline Antrostomus carolinensis & 64 FFQYYGNWPKPTSLSGGALVR 84 \\
\hline Aotus nancymaae & 178 FFQFFGGWPKPASLSGGAMVR 198 \\
\hline Aptenodytes forsteri & 178 FFQYYGNWPKPTSLSGGSLVR 198 \\
\hline Astyanax mexicanus & 183 YFQFFGNWSKPASLSGGTLMH 203 \\
\hline Balaenoptera acutorostrata scammoni & 151 FFQFFGGWPKPASLSGGAMVR 171 \\
\hline Boleophthalmus pectinirostris & 184 YFQFYGNWPKPVSLSGGSLLH 204 \\
\hline Bos indicus & 178 FFQFFGGWPKPASLSGGAMVR 198 \\
\hline Bos mutus & 134 FFQFFGGWPKPASLSGGAMVR 154 \\
\hline Bos taurus & 178 FFQFFGGWPKPASLSGGAMVR 198 \\
\hline Bubalus bubalis & 178 FFQFFGGWPKPASLSGGAMVR 198 \\
\hline Calidris pugnax & 178 FFQYYGNWPKPTSLSGGALVR 198 \\
\hline Callithrix jacchus & 289 FFQFFGGWPKPASLSGGAMVR 309 \\
\hline Callorhinchus milii & 180 FFQFYGNWTKPVSLSGGSLVH 200 \\
\hline Calypte anna & 180 FFQYYGNWPKPTSLSGGALVR 200 \\
\hline Camelus bactrianus & 178 FFQFFGGWPKPASLSGGAMVR 198 \\
\hline Camelus ferus & 90 FFQFFGGWPKPASLSGGAMVR 110 \\
\hline Canis lupus & 189 FFQFFGGWPKPASLSGGAMVR 209 \\
\hline Capra hircus & 178 FFQFFGGWPKPASLSGGAMVR 198 \\
\hline Castor canadensis & 238 FFQFFGGWPKPASLSGGAMVR 258 \\
\hline Cavia porcellus & 178 FFQFFGGWPKPASLSGGAMVR 198 \\
\hline Ceratotherium simum simum & 178 FFQFFGGWPKPASLSGGAMVR 198 \\
\hline Cercocebus atys & 178 FFQFFGGWPKPASLSGGAMVR 198 \\
\hline Chaetura pelagica & 150 FFQYYGNWPKPTSLSGGALVR 170 \\
\hline Charadrius vociferus & 177 FFQYYGNWPKPTSLSGGALVR 197 \\
\hline Chelonia mydas & 176 FFQFYGNWPKPTSLSGGALVR 196 \\
\hline Chinchilla lanigera & 178 FFQFFGGWPKPASLSGGTMVR 198 \\
\hline Chlorocebus sabaeus & 178 FFQFFGGWPKPASLSGGAMVR 198 \\
\hline Chrysemys picta & 181 FFQFYGNWPKPTSLSGGALVR 201 \\
\hline
\end{tabular}


Table A2. Cont.

\begin{tabular}{|c|c|}
\hline Species & Amino Acid Snippet \\
\hline Chrysochloris asiatica & 178 FFQFFGGWPKPASLSGGAMVR 198 \\
\hline Clupea harengus & 183 YFQFFGNWSKPASLSGGTLAH 203 \\
\hline Columba livia & 178 FFQYYGNWPKPTSLSGGSLVR 198 \\
\hline Condylura cristata & 276 FFQFFGGWPKPTSLSGGAMVR 296 \\
\hline Corvus brachyrhynchos & 178 FFQYYGNWPKPTSLSGGTLVR 198 \\
\hline Coturnix japonica & 182 FFQYYGNWPKPTSLSGGALVR 202 \\
\hline Cricetulus griseus & 273 FFQFFGGWPKPASLSGGAMVR 293 \\
\hline Crocodylus porosus & 176 FFQFYGNWPKPASLSGGSLVR 196 \\
\hline Cuculus canorus & 178 FFQYYGNWPKPTSLSGGALVR 198 \\
\hline Cynoglossus semilaevis & 187 YFQFYGNWPKPASLSGGSLLH 207 \\
\hline Cyprinodon variegatus & 185 YFQFYGNWPKPASLSGGSLLH 205 \\
\hline Cyprinus carpio & 183 YFQIFGNWSKPASLSGGTLVH 203 \\
\hline Danio rerio & 183 YFQIFGNWSKPASLSGGTLVH 203 \\
\hline Dasypus novemcinctus & 178 FFQFFGGWPKPASLSGGAMVR 198 \\
\hline Dipodomys ordii & 130 FFQFFGGWPKPASLSGGAMVR 150 \\
\hline Egretta garzetta & 178 FFQYYGNWPKPTSLSGGALVR 198 \\
\hline Elephantulus edwardii & 178 FFQFFGGWPKPASLSGGAMVR 198 \\
\hline Eptesicus fuscus & 80 FFQVFGGWPKPASLSGGAMVR 100 \\
\hline Equus asinus & 178 FFQFFGGWPKPASLSGGAMVR 198 \\
\hline Equus caballus & 178 FFQFFGGWPKPASLSGGAMVR 198 \\
\hline Equus przewalskii & 60 FFQFFGGWPKPASLSGGAMVR 80 \\
\hline Erinaceus europaeus & 322 FFQFFGGWPKPTSLSGGAMVR 342 \\
\hline Esox lucius & 183 YFQFYGNWPKPVSLTGGSLLH 203 \\
\hline Falco cherrug & 178 FFQYYGNWPKPTSLSGGALVR 198 \\
\hline Falco peregrinus & 178 FFQYYGNWPKPTSLSGGALVR 198 \\
\hline Felis catus & 178 FFQFFGGWPKPASLSGGAMVR 198 \\
\hline Ficedula albicollis & 178 FFQYYGNWPKPTSLSGGTLVR 198 \\
\hline Fukomys damarensis & 178 FFQFFGGWPKPASLSGGAMVR 198 \\
\hline Fundulus heteroclitus & 185 YFQYYGNWSKPASLSGGTMLH 205 \\
\hline Gadus morhua & 245 YFQFYGNWPKPASLSGGTMLH 265 \\
\hline Galeopterus variegatus & 92 FFQFFGGWPKPASLSGGAMVR 112 \\
\hline Gallus gallus & 182 FFQYYGNWPKPTSLSGGALVR 202 \\
\hline Gavialis gangeticus & 176 FFQFYGNWPKPASLSGGSLVR 196 \\
\hline Geospiza fortis & 178 FFQYYGNWPKPTSLSGGTLVR 198 \\
\hline Gorilla gorilla & 178 FFQFFGGWPKPASLSGGAMVR 198 \\
\hline Haliaeetus leucocephalus & 178 FFQYYGNWPKPTSLSGGALVR 198 \\
\hline Haplochromis burtoni & 185 YFQFYGNWPKPASLSGGSLLH 205 \\
\hline Heterocephalus glaber & 178 FFQFFGGWPKPASLSGGAMVR 198 \\
\hline Hippocampus comes & 185 YFQFFGNWPKPVSLSGGSLLH 205 \\
\hline Hipposideros armiger & 236 FFQFFGGWPKPASLSGGTMVR 256 \\
\hline Ictalurus punctatus & 183 YFQMFGNWSKPASLSGGTLLH 203 \\
\hline Ictidomys tridecemlineatus & 178 FFQFFGGWPKPASLSGGAMVR 198 \\
\hline Jaculus jaculus & 179 FFQFFGGWPKPASLSGGAMVR 199 \\
\hline Kryptolebias marmoratus & 224 YFQIYGNWSKPASLSGGSLLH 244 \\
\hline Labrus bergylta & 185 YFQFYGNWPKPASLSGGSLLH 205 \\
\hline Larimichthys crocea & 185 YFQFFYGNWPKPASLSGGSLLH 205 \\
\hline Lates calcarifer & 185 YFQFYGNWPKPASLSGGSLLH 205 \\
\hline Latimeria chalumnae & 179 FFQFYGGWPKPSSLSGGTLLH 199 \\
\hline Lepidothrix coronata & 178 FFQYYYGNWPKPTSLSGGTLVR 198 \\
\hline Lepisosteus oculatus & 183 YFQYYGNWPKPASLSGGSLLH 203 \\
\hline Leptonychotes weddellii & 153 FFQFFGGWPKPASLSGGAMVR 173 \\
\hline Leptosomus discolor & 178 FFQYYGNWPKPTSLSGGALVR 198 \\
\hline Lipotes vexillifer & 178 FFQFFGGWPKPASLSGGAMVR 198 \\
\hline Loxodonta africana & 178 FFQFFGGWPKPASLSGGAMVR 198 \\
\hline Macaca fascicularis & 327 FFQFFGGWPKPASLSGGAMVR 347 \\
\hline Macaca mulatta & 327 FFQFFGGWPKPASLSGGAMVR 347 \\
\hline Macaca nemestrina & 178 FFQFFGGWPKPASLSGGAMVR 198 \\
\hline
\end{tabular}


Table A2. Cont.

\begin{tabular}{|c|c|}
\hline Species & Amino Acid Snippet \\
\hline Manacus vitellinus & 178 FFQYYGNWPKPTSLSGGTLVR 198 \\
\hline Mandrillus leucophaeus & 166 FFQFFGGWPKPASLSGGAMVR 186 \\
\hline Manis javanica & 178 FFQFFFGWPKPASLSGGAMVR 198 \\
\hline Marmota marmota marmota & 88 FFQFFGGWPKPASLSGGAMVR 108 \\
\hline Maylandia zebra & 185 YFQFYGNWPKPASLSGGSLLH 205 \\
\hline Meleagris gallopavo & 178 FFQYYGNWPKPTSLSGGALVR 198 \\
\hline Melopsittacus undulatus & 178 FFQYYGNWPKPTSLSGGALVR 198 \\
\hline Mesitornis unicolor & 182 FFQYYGNWPKPTSLSGGALVR 202 \\
\hline Mesocricetus auratus & 203 FFQFFGGWPKPASLSGGAMVR 223 \\
\hline Microcebus murinus & 178 FFQFFGGWPKPASLSGGAMVR 198 \\
\hline Microtus ochrogaster & 178 FFQFFGGWPKPASLSGGAMVR 198 \\
\hline Monodelphis domestica & 261 FFQFFGGWPKPASLSGGALVR 281 \\
\hline Monopterus albus & 185 YFQFFYGNWSKPASLSGGSLLH 205 \\
\hline Mus musculus & 178 FFQYFGGWPKPASLSGGAMVR 198 \\
\hline Mustela putorius furo & 178 FFQFFGGWPKPASLSGGAMVR 198 \\
\hline Myotis brandtii & 51 FFQFFGGWPKPASLSGGAMVR 71 \\
\hline Myotis lucifugus & 120 FFQFFGGWPKPASLSGGAMVR 140 \\
\hline Nannospalax galili & 178 FFQFFGGWPKPASLSGGAMVR 198 \\
\hline Nipponia nippon & 178 FFQYYGNWPKPTSLSGGALVR 198 \\
\hline Nomascus leucogenys & 201 FFQFFGGWPKPASLSGGAMVR 221 \\
\hline Nothobranchius furzeri & 198 YFQFYGNWPKPASLSGGSLLH 218 \\
\hline Notothenia coriiceps & 185 YFQYYYGNWPKPASLSGGSLLH 205 \\
\hline Ochotona princeps & 179 FFQFFGGWPKPASLSGGAMVR 199 \\
\hline Octodon degus & 178 FFQFFGGWPKPASLSGGAMVR 198 \\
\hline Odobenus rosmarus divergens & 178 FFQFFGGWPKPASLSGGAMVR 198 \\
\hline Oncorhynchus kisutch & 186 YFQFYGNWPKPASLSGGSLLH 206 \\
\hline Oncorhynchus mykiss & 184 YFQFFYGNWPKPASLSGGSLLH 204 \\
\hline Orcinus orca & 178 FFQFFGGWPKPASLSGGTMVR 198 \\
\hline Oreochromis niloticus & 185 YFQFYGNWPKPASLSGGSLLH 205 \\
\hline Ornithorhynchus anatinus & 181 FFQFFFGGWPKPASLSGGALVR 201 \\
\hline Orycteropus afer afer & 178 FFQFFGGWPKPASLSGGAMVR 198 \\
\hline Oryctolagus cuniculus & 178 FFQFFGGWPKPASLSGGAMVR 198 \\
\hline Oryzias latipes & 183 YFQFYGSWPKPASLSGGSLLH 203 \\
\hline Otolemur garnettii & 178 FFQFFGGWPKPASLSGGAMVR 198 \\
\hline Ovis aries & 178 FFQFFGGWPKPASLSGGAMVR 198 \\
\hline Pan paniscus & 178 FFQFFGGWPKPASLSGGAMVR 198 \\
\hline Pan troglodytes & 178 FFQFFGGWPKPASLSGGAMVR 198 \\
\hline Panthera pardus & 178 FFQFFGGWPKPASLSGGAMVR 198 \\
\hline Panthera tigris altaica & 79 FFQFFGGWPKPASLSGGAMVR 99 \\
\hline Pantholops hodgsonii & 91 FFQFFGGWPKPASLSGGAMVR 111 \\
\hline Papio anubis & 178 FFQFFGGWPKPASLSGGAMVR 198 \\
\hline Paralichthys olivaceus & 185 YFQFYGNWPKPGSLSGGSLLH 205 \\
\hline Parus major & 178 FFQYYGNWPKPTSLSGGSLVR 198 \\
\hline Pelodiscus sinensis & 176 FFQFYGNWPKPTSLSGGALVR 196 \\
\hline Peromyscus maniculatus bairdii & 273 FFQFFGGWPKPASLSGGAMVR 293 \\
\hline Phascolarctos cinereus & 178 FFQFFGGWPKPASLSGGALVR 198 \\
\hline Physeter catodon & 234 FFQFFGGWPKPASLSGGAMVR 254 \\
\hline Picoides pubescens & 182 FFQYYGNWPKPTSLSGGALVR 202 \\
\hline Poecilia formosa & 185 YFQFFYGNWPKPASLSGGSLLH 205 \\
\hline Poecilia latipinna & 185 YFQFYGNWPKPASLSGGSLLH 205 \\
\hline Poecilia reticulata & 185 YFQFYGNWPKPASLSGGSLLH 205 \\
\hline Pogona vitticeps & 182 FFQFYGNWPKPTSLSGGVLVR 202 \\
\hline Pongo abelii & 178 FFQFFGGWPKPASLSGGAMVR 198 \\
\hline Propithecus coquereli & 178 FFQFFGGWPKPASLSGGAMVR 198 \\
\hline Pseudopodoces humilis & 178 FFQYYGNWPKPTSLSGGSLVR 198 \\
\hline Pteropus alecto & 225 FFQFFGGWPKPASLSGGAMVR 245 \\
\hline Pteropus vampyrus & 225 FFQFFGGWPKPASLSGGAMVR 245 \\
\hline
\end{tabular}


Table A2. Cont.

\begin{tabular}{cc}
\hline Species & Amino Acid Snippet \\
\hline Pundamilia nyererei & 185 YFQFYGNWPKPASLSGGSLLH 205 \\
Pygocentrus nattereri & 193 YFQIFGNWSKPASLSGGTLLH 213 \\
Python bivittatus & 189 FFQFYGNWPKPTSLSGGSLVR 209 \\
Rattus norvegicus & 178 FFQFFGGWPKPASLSGGAMVR 198 \\
Rhinolophus sinicus & 178 FFQFFGGWPKPASLSGGTMVR 198 \\
Rhinopithecus bieti & 178 FFQFFGGWPKPASLSGGAMVR 198 \\
Rhinopithecus roxellana & 178 FFQFFGGWPKPASLSGGAMVR 198 \\
Rousettus aegyptiacus & 178 FFQFFGGWPKPASLSGGAMVR 198 \\
Saimiri boliviensis & 178 FFQFFGGWPKPASLSGGAMVR 198 \\
Salmo salar & 186 YFQFYGNWPKPASLSGGSLLH 206 \\
Sarcophilus harrisii & 154 FFQFFGGWPKPASLSGGALVR 174 \\
Scleropages formosus & 182 YFQFYANWPKPASLSGGSLLH 202 \\
Sorex araneus & 178 FFQFFGGWPKPASLSGGTMVR 198 \\
Stegastes partitus & 185 YFQFYGNWPKPASLSGGSLLH 205 \\
Sturnus vulgaris & 178 FFQYYGNWPKPTSLSGGTLVR 198 \\
Sus scrofa & 195 FFQFFGGWPKPASLSGGAMVR 215 \\
Taeniopygia guttata & 251 FFQYYGNWPKPTSLSGGTLVR 271 \\
Takifugu rubripes & 231 YFQFYGNWPKPVSLSGSSLLH 251 \\
Tauraco erythrolophus & 168 FFQYYGNWPKPTSLSGGALVR 188 \\
Tinamus guttatus & 182 FFQYYGNWPKPTSLSGGALVR 202 \\
Trichechus manatus latirostris & 178 FFQFFGGWPKPASLSGGAMVR 198 \\
Tupaia chinensis & 178 FFQFFGGWPKPASLSGGAMVR 198 \\
Ursus maritimus & 55 FFQFFGGWPKPASLSGGAMVR 75 \\
Vicugna pacos & 131 FFQFFGGWPKPASLSGGAMVR 151 \\
Xenopus tropicalis & 179 FFQL-GDAKKPVGLCGGAALR 198 \\
Xiphophorus maculatus & 185 YFQFYGNWPKPASLSGGSLLH 205
\end{tabular}

Orthologous sequences were obtained from NCBI and aligned using ClustalW. The conserved glutamine residue is shown in red.

A
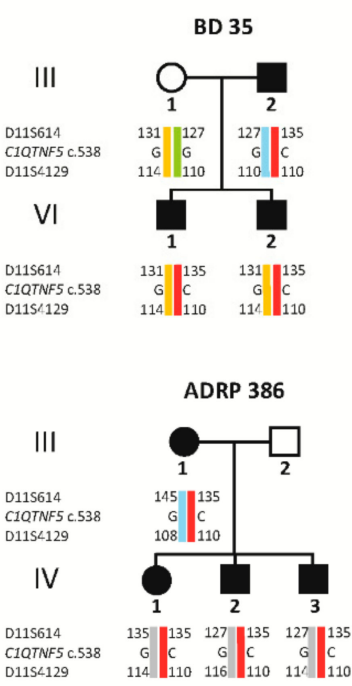

B

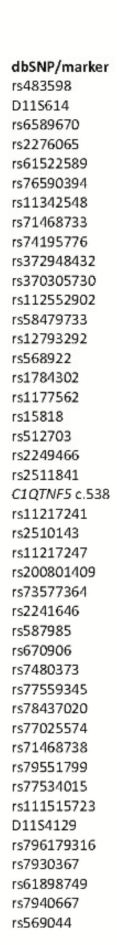

Chromosome 11

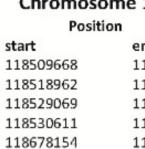

118530611
118678154

118678155

11867815

118733817

118742566

18742607

11874261

11891920
118940957

11894933

11895217

119005088

11920637

119213303

11921623

11921956

119219572

11922220

119229964
119244095

119252199

119356997

119357002

1935700

19357004

11935702

119357026

119379575

11939454

11940997

11942031

119445504

119510644
119999191

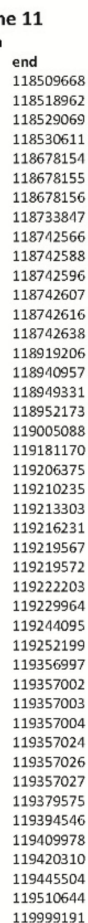

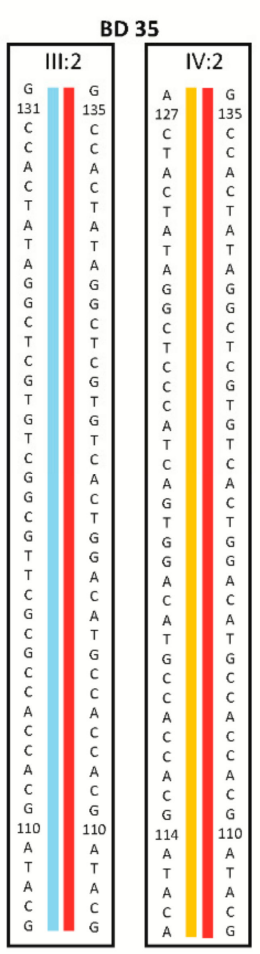

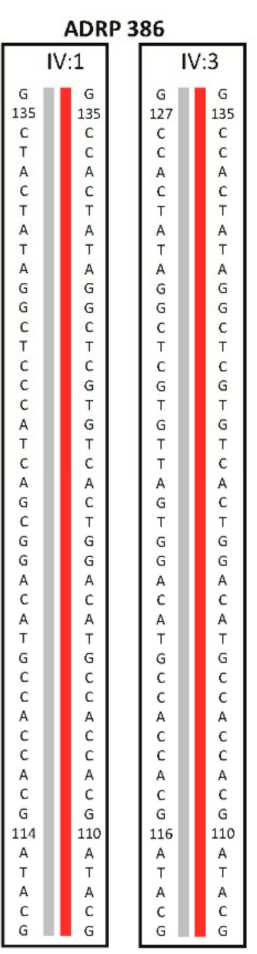

Figure A1. Haplotype analysis showing that the p.(Q180E) variant found in families BD 35 and ADRP 386 is identical by descent. (A) Pedigrees showing the core families. Genotypes of the C1QTNF5 variant and two microsatellites surrounding the gene are depicted below the respective pedigree symbols. The shared haplotype of the p.(Q180E) variant is indicated by 
red colored bars. (B) Extended haplotype analysis using informative genotype data of 41 SNPs spanning a physical region of $2 \mathrm{Mb}$ interval surrounding C1QTNF5. Note that SNP genotypes were deduced from whole genome sequencing data that was only available for individuals III:2 and IV:2 from family BD 35, and for individuals IV:1 and IV:3 from family ADRP 386, respectively. The shared haplotype of the p.(Q180E) variant is indicated by red colored bars. Genomic coordinates refer to GRCh37/hg19. Ref, reference allele.

\section{References}

1. Montioli, R.; Bellezza, I.; Desbats, M.A.; Voltattorni, C.B.; Salviati, L.; Cellini, B. Deficit of human ornithine aminotransferase in gyrate atrophy: Molecular, cellular, and clinical aspects. Biochim. Biophys. Acta BBA Proteins Proteom. 2021, $1869,140555$. [CrossRef]

2. Shen, L.L.; Ahluwalia, A.; Sun, M.; Young, B.K.; Nardini, H.K.G.; Del Priore, L.V. Long-term natural history of visual acuity in eyes with choroideremia: A systematic review and meta-analysis of data from 1004 individual eyes. Br. J. Ophthalmol. 2021, 105, 271-278. [CrossRef]

3. Bowne, S.J.; Humphries, M.M.; Sullivan, L.S.; Kenna, P.F.; Tam, L.C.S.; Kiang, A.S.; Campbell, M.; Weinstock, G.M.; Koboldt, D.C.; Ding, L.; et al. A dominant mutation in RPE65 identified by whole-exome sequencing causes retinitis pigmentosa with choroidal involvement. Eur. J. Hum. Genet. 2011, 19, 1074-1081. [CrossRef] [PubMed]

4. Tsunoda, K.; Fujinami, K.; Yoshitake, K.; Iwata, T. Late-onset night blindness with peripheral flecks accompanied by progressive trickle-like macular degeneration. Doc. Ophthalmol. 2019, 139, 171-184. [CrossRef]

5. Hayasaka, S.; Shoji, K.; Kanno, C.-I.; Oura, F.; Mizuno, K. Differential diagnosis of diffuse choroidal atrophies. Retina 1985, 5, 30-37. [CrossRef]

6. Marchesani, O.; Sautter, H. Atlas des Augenhintergrundes; Urban \& Schwarzenberg: München, Germany, $1957 ;$ Volume 2.

7. Kellner, U.; Weleber, R.G.; Kennaway, N.G.; Fishman, G.A.; Foerster, M.H. Gyrate atrophy-like phenotype with normal plasma ornithine. Retina 1997, 17, 403-413. [CrossRef] [PubMed]

8. Kuntz, A.C.; Jacobson, S.G.; Cideciyan, A.V.; Li, Z.Y.; Stone, E.M.; Possin, D.; Milam, A.H. Sub-retinal pigment epithelial deposits in a dominant late-onset retinal degeneration. Investig. Ophthalmol. Vis. Sci. 1996, 37, 1772-1782.

9. Duvall, J.; McKechnie, N.M.; Lee, W.R.; Rothery, S.; Marshall, J. Extensive subretinal pigment epithelial deposit in two brothers suffering from dominant retinitis pigmentosa. Graefe's Arch. Clin. Exp. Ophthalmol. 1986, 224, 299-309. [CrossRef]

10. Brosnahan, D.M.; Kennedy, S.M.; Converse, C.A.; Lee, W.R.; Hammer, H.M. Pathology of hereditary retinal degeneration associated with hypobetalipoproteinemia. Ophthalmology 1994, 101, 38-45. [CrossRef]

11. Hayward, C.; Shu, X.; Cideciyan, A.V.; Lennon, A.; Barran, P.; Zareparsi, S.; Sawyer, L.; Hendry, G.; Dhillon, B.; Milam, A.H.; et al Mutation in a short-chain collagen gene, CTRP5, results in extracellular deposit formation in late-onset retinal degeneration: A genetic model for age-related macular degeneration. Hum. Mol. Genet. 2003, 12, 2657-2667. [CrossRef] [PubMed]

12. Stanton, C.M.; Borooah, S.; Drake, C.; Marsh, J.A.; Campbell, S.; Lennon, A.; Soares, D.C.; Vallabh, N.A.; Sahni, J.; Cideciyan, A.V.; et al. Novel pathogenic mutations in C1QTNF5 support a dominant negative disease mechanism in late-onset retinal degeneration. Sci. Rep. 2017, 7, 12147. [CrossRef] [PubMed]

13. Borooah, S.; Stanton, C.M.; Marsh, J.; Carss, K.J.; Waseem, N.; Biswas, P.; Agorogiannis, G.; Raymond, L.; Arno, G.; Webster, A.R. Whole genome sequencing reveals novel mutations causing autosomal dominant inherited macular degeneration. Ophthalmic Genet. 2018, 39, 763-770. [CrossRef] [PubMed]

14. Wong, G.W.; Krawczyk, S.A.; Kitidis-Mitrokostas, C.; Revett, T.; Gimeno, R.; Lodish, H.F. Molecular, biochemical and functional characterizations of C1q/TNF family members: Adipose-tissue-selective expression patterns, regulation by PPAR- $\gamma$ agonist, cysteine-mediated oligomerizations, combinatorial associations and metabolic functions. Biochem. J. 2008, 416, 161-177. [CrossRef] [PubMed]

15. Mandal, M.N.A.; Vasireddy, V.; Jablonski, M.M.; Ayyagari, R.; Reddy, G.B.; Wang, X.; Moroi, S.E.; Pattnaik, B.R.; Hughes, B.A.; Heckenlively, J.R.; et al. CTRP5 is a membrane-associated and secretory protein in the rpe and ciliary body and the S163R mutation of CTRP5 impairs its secretion. Investig. Opthalmol. Vis. Sci. 2006, 47, 5505-5513. [CrossRef]

16. Tu, X.; Palczewski, K. Crystal structure of the globular domain of C1QTNF5: Implications for late-onset retinal macular degeneration. J. Struct. Biol. 2012, 180, 439-446. [CrossRef]

17. Shu, X.; Tulloch, B.; Lennon, A.; Vlachantoni, D.; Zhou, X.; Hayward, C.; Wright, A.F. Disease mechanisms in late-onset retinal macular degeneration associated with mutation in C1QTNF5. Hum. Mol. Genet. 2006, 15, 1680-1689. [CrossRef] [PubMed]

18. Tu, X.; Palczewski, K. The macular degeneration-linked C1QTNF5 (S163) mutation causes higher-order structural rearrangements. J. Struct. Biol. 2014, 186, 86-94. [CrossRef]

19. Shapiro, L.; Scherer, P.E. The crystal structure of a complement-1q family protein suggests an evolutionary link to tumor necrosis factor. Curr. Biol. 1998, 8, 335-340. [CrossRef]

20. Dell'Orco, D.; Xue, W.-F.; Thulin, E.; Linse, S. Electrostatic contributions to the kinetics and thermodynamics of protein assembly. Biophys. J. 2005, 88, 1991-2002. [CrossRef] [PubMed] 
21. Milam, A.H.; Curcio, A.C.; Cideciyan, A.V.; Saxena, S.; John, S.K.; Kruth, H.S.; Malek, G.; Heckenlively, J.R.; Weleber, R.G.; Jacobson, S.G. Dominant late-onset retinal degeneration with regional variation of sub-retinal pigment epithelium deposits, retinal function, and photoreceptor degeneration. Ophthalmology 2000, 107, 2256-2266. [CrossRef]

22. Borooah, S.; Collins, C.; Wright, A.; Dhillon, B. Late-onset retinal macular degeneration: Clinical insights into an inherited retinal degeneration. Postgrad. Med. J. 2009, 85, 495-500. [CrossRef]

23. Vincent, A.; Munier, F.L.; VandenHoven, C.C.; Wright, T.; Westall, C.A.; Héon, E. The characterization of retinal phenotype in a family with c1qtnf5-related late-onset retinal degeneration. Retina 2012, 32, 1643-1651. [CrossRef]

24. Mandal, N.; Lotery, A.J. Multimodal imaging of late-onset retinal degeneration complicated by bilateral choroidal neovascularization. Eye 2019, 33, 1020-1027. [CrossRef]

25. Papastavrou, V.T.; O’Brien, J.M.; Regan, A.J.; Aftab, A.M.; Browning, A.C. The progression of macular structural and func-tional changes in late-onset retinal degeneration. Retin. Cases Brief. Rep. 2020. [CrossRef] [PubMed]

26. Borooah, S.; Papastavrou, V.T.; Browning, A.C.; Lando, L.; Moghimi, S.; Lin, T.; Dans, K.; Motevasseli, T.; Cameron, J.R.; Freeman, W.R.; et al. Characterizing the natural history of foveal-sparing atrophic late-onset retinal degeneration. Retina 2020. [CrossRef]

27. Borooah, S.; Collins, C.; Wright, A.; Dhillon, B. Late-onset retinal macular degeneration: Clinical insights into an inherited retinal degeneration. Br. J. Ophthalmol. 2009, 93, 284-289. [CrossRef] [PubMed]

28. Ayyagari, R.; Mandal, N.A.; Maumenee, I.H.; Sieving, P.A.; Karoukis, A.J.; Chen, L.; McLaren, N.C.; Lichter, M.; Wong, D.T.; Hitchcock, P.F.; et al. Late-onset macular degeneration and long anterior lens zonules result from ACTRP5gene mutation. Investig. Opthalmol. Vis. Sci. 2005, 46, 3363-3371. [CrossRef] [PubMed]

29. Khan, K.N.; Borooah, S.; Webster, A.R.; Moore, A.T.; McKibbin, M.; Michaelides, M.; Lando, L.; Dans, K.; Mahroo, O.A.; Meshi, A.; et al. Quantifying the separation between the retinal pigment epithelium and bruch's membrane using optical coherence tomography in patients with inherited macular degeneration. Transl. Vis. Sci. Technol. 2020, 9, 26. [CrossRef]

30. Ramtohul, P.; Gascon, P.; Matonti, F. Choroidal neovascularization in late-onset retinal macular degeneration. Ophthalmol. Retin. 2019, 3, 153. [CrossRef]

31. Cukras, C.; Flamendorf, J.; Wong, W.T.; Ayyagari, R.; Cunningham, D.; Sieving, P.A. Longitudinal structural changes in late-onset retinal degeneration. Retina 2016, 36, 2348-2356. [CrossRef]

32. Soumplis, V.; Sergouniotis, P.I.; Robson, A.G.; Michaelides, M.; Moore, A.T.; Holder, G.E.; Webster, A.R. Phenotypic findings inC1QTNF5retinopathy (late-onset retinal degeneration). Acta Ophthalmol. 2013, 91, e191-e195. [CrossRef]

33. Papastavrou, V.T.; Bradshaw, K.R.; Aye, K.H.; Turney, C.; Browning, A.C. Improvement of retinal function in L-ORD after prolonged dark adaptation. Can. J. Ophthalmol. 2015, 50, 112-118. [CrossRef]

34. Troumani, Y.; Beral, L.; David, T. Traitement d'une membrane néovasculaire choroïdienne chez un patient présentant une dystrophie rétinienne autosomique dominante rare par aflibercept: À propos d'un cas. J. Français d'Ophtalmol. 2015, 38, e67-e69. [CrossRef] [PubMed]

35. Aye, K.H.; Gupta, R.; Talks, S.J.; Browning, A.C. Treatment of a choroidal neovascular membrane in a patient with late-onset retinal degeneration (L-ORD) with intravitreal Ranibizumab. Eye 2010, 24, 1528-1530. [CrossRef] [PubMed]

36. Jacobson, S.G.; Cideciyan, A.V.; Sumaroka, A.; Roman, A.J.; Wright, A.F. Late-onset retinal degeneration caused byC1QTNF5mutation. JAMA Ophthalmol. 2014, 132, 1252. [CrossRef]

37. Almoguera, B.; Li, J.; Garcia-Sandoval, B.; Guo, Y.; Tian, L.; Liu, X.; Guan, L.; Zhang, J.; Keating, B.; Xu, X.; et al. Application of whole exome sequencing in six families with an initial diagnosis of autosomal dominant retinitis pigmentosa: Lessons learned. PLoS ONE 2015, 10, e0133624. [CrossRef] [PubMed]

38. Ayyagari, R.; Griesinger, I.B.; Bingham, E.; Lark, K.K.; Moroi, S.E.; Sieving, P.A. Autosomal dominant hemorrhagic macular dystrophy not associated with the TIMP3 gene. Arch. Ophthalmol. 2000, 118, 85-92. [CrossRef]

39. Subrayan, V.; Morris, B.; Armbrecht, A.M.; Wright, A.F.; Dhillon, B. Long anterior lens zonules in late-onset retinal degeneration (L-ORD). Am. J. Ophthalmol. 2005, 140, 1127-1129. [CrossRef] [PubMed]

40. Roberts, D.K.; Ayyagari, R.; Moroi, S.E. Possible association between long anterior lens zonules and plateau iris configuration. J. Glaucoma 2008, 17, 393-396. [CrossRef]

41. Papastavrou, V.T.; Borooah, S.; O’Brien, J.M.; Ray-Chaudhuri, N.; Dhillon, B.; Vieira, R.V.; Browning, A.C. Cataract surgery in patients with late-onset retinal degeneration. J. Cataract. Refract. Surg. 2017, 43, 1036-1043. [CrossRef]

42. Mandal, N.A.; Vasireddy, V.; Jablonski, M.M.; Wang, X.; Heckenlively, J.R.; Hughes, B.A.; Reddy, G.B.; Ayyagari, R. Spatial and temporal expression of MFRP and its interaction with CTRP5. Investig. Opthalmol. Vis. Sci. 2006, 47, 5514-5521. [CrossRef]

43. Chekuri, A.; Zientara-Rytter, K.; Soto-Hermida, A.; Borooah, S.; Voronchikhina, M.; Biswas, P.; Kumar, V.; Goodsell, D.; Hayward, C.; Shaw, P.; et al. Late-onset retinal degeneration pathology due to mutations in CTRP5 is mediated through HTRA1. Aging Cell 2019, 18, e13011. [CrossRef]

44. Dinculescu, A.; Dyka, F.M.; Min, S.-H.; Stupay, R.M.; Hooper, M.J.; Smith, W.C.; Hauswirth, W.W. Co-expression of wild-type and mutant S163R C1QTNF5 in retinal pigment epithelium. Results Probl. Cell Differ. 2018, 1074, 61-66. [CrossRef]

45. Dinculescu, A.; Min, S.-H.; Dyka, F.M.; Deng, W.-T.; Stupay, R.M.; Chiodo, V.; Smith, W.C.; Hauswirth, W.W. Pathological effects of mutant C1QTNF5 (S163R) expression in murine retinal pigment epithelium. Investig. Opthalmol.Vis. Sci. 2015, 56, 6971-6980. [CrossRef]

46. Lewis, T.R.; Makia, M.S.; Kakakhel, M.; Al-Ubaidi, M.R.; Arshavsky, V.Y.; Naash, M.I. Photoreceptor disc enclosure occurs in the absence of normal peripherin-2/RDS oligomerization. Front. Cell. Neurosci. 2020, 14, 92. [CrossRef] [PubMed] 
47. Okuda, A.; Naganuma, T.; Ohno, Y.; Abe, K.; Yamagata, M.; Igarashi, Y.; Kihara, A. Hetero-oligomeric interactions of an ELOVL4 mutant protein: Implications in the molecular mechanism of Stargardt-3 macular dystrophy. Mol. Vis. 2010, 16, $2438-2445$. [PubMed]

48. Kuehlewein, L.; Zobor, D.; Andreasson, S.O.; Ayuso, C.; Banfi, S.; Bocquet, B.; Bernd, A.S.; Biskup, S.; Boon, C.J.F.; Downes, S.M.; et al. Clinical phenotype and course of pde6a-associated retinitis pigmentosa disease, characterized in preparation for a gene supplementation trial. JAMA Ophthalmol. 2020, 138, 1241-1250. [CrossRef]

49. Kellner, S.; Stöhr, H.; Fiebig, B.; Weinitz, S.; Farmand, G.; Kellner, U.; Weber, B.H.F. Fundus autofluorescence and SD-oct document rapid progression in autosomal dominant vitreoretinochoroidopathy (ADVIRC) Associated with a C.256G> A mutation in BEST1. Ophthalmic Genet. 2016, 37, 201-208. [CrossRef] [PubMed]

50. Hood, D.C.; Bach, M.; Brigell, M.; Keating, D.; Kondo, M.; Lyons, J.S.; Marmor, M.F.; McCulloch, D.L.; Palmowski-Wolfe, A.M.; International Society for Clinical Electrophysiology of Vision. ISCEV standard for clinical multifocal electroretinography (mfERG) (2011 edition). Doc. Ophthalmol. 2011, 124, 1-13. [CrossRef]

51. McCulloch, D.L.; Marmor, M.F.; Brigell, M.G.; Hamilton, R.; Holder, G.E.; Tzekov, R.; Bach, M. ISCEV Standard for full-field clinical electroretinography (2015 update). Doc. Ophthalmol. 2015, 130, 1-12. [CrossRef]

52. Weisschuh, N.; Mazzola, P.; Heinrich, T.; Haack, T.; Wissinger, B.; Tonagel, F.; Kelbsch, C. First submicroscopic inversion of the OPA1 gene identified in dominant optic atrophy-a case report. BMC Med. Genet. 2020, 21, 1-6. [CrossRef] [PubMed]

53. Mayer, A.K.; Van Cauwenbergh, C.; Rother, C.; Baumann, B.; Reuter, P.; De Baere, E.; Wissinger, B.; Kohl, S.; ACHM Study Group. CNGB3 mutation spectrum including copy number variations in 552 achromatopsia patients. Hum. Mutat. 2017, 38, 1579-1591. [CrossRef] [PubMed]

54. Sankar, K.; Krystek, S.R.; Carl, S.M.; Day, T.; Maier, J.K.X. AggScore: Prediction of aggregation-prone regions in proteins based on the distribution of surface patches. Proteins Struct. Funct. Bioinform. 2018, 86, 1147-1156. [CrossRef] [PubMed] 